\title{
Insights in the Mechanism of Selective Olefin Oligomerisation Catalysis using Stopped-Flow Freeze-Quench Techniques: a Mo K edge QEXAFS Study
}

Stuart A. Bartlett, ${ }^{1}$ Peter P. Wells, ${ }^{1}$ Maarten Nachtegaal, ${ }^{2}$ Andrew J. Dent, ${ }^{3}$ Giannantonio Cibin, ${ }^{3}$ Gillian Reid, ${ }^{1}$ John Evans, ${ }^{1}$ Moniek Tromp ${ }^{4}$,

${ }^{1}$ School of Chemistry, University of Southampton, Highfield, Southampton,

SO17 1BJ, UK; ${ }^{2}$ Swiss Light Source, Paul Scherrer Institut, 5232 Villigen, Switzerland;

${ }^{3}$ Diamond Light Source Ltd, Didcot, OX11 ODE, UK;4Strukturanalytik in der Katalyse, Chemie, Catalysis Research Centre, Technische Universität München, Lichtenbergstrasse 4 , 85748 Garching, Germany, Tel. +49-89-28912813, Fax. +49-89-28912866,

moniek.tromp@tum.de

School of Chemistry, University of Southampton, Southampton UK SO17 1BJ. E-mail:

je@soton.ac.uk

Please cite this paper as:

Journal of Catalysis, 201 1, 284, 247-258

The publisher's version of this paper is available here:

http://dx.doi.org/10.1016/j.jcat.2011.10.015

\section{Related articles by Prof John Evans can be found below:}

Jerome O. Moulin, John Evans, David S. McGuinness, Gillian Reid, Adam J. Rucklidge, Robert P. Tooze and Moniek Tromp (2008) Probing the effects of ligand structure on activity and selectivity of Cr(III) complexes for ethylene oligomerisation and polymerization, Dalton Transactions, 1177-1185.

(DOI: 10.1039/B716078J)

Stuart A. Bartlett, Giannantonio Cibin, Andrew J. Dent, John Evans, Martin J. Hanton, Gillian Reid, Robert P. Tooze, and Moniek Tromp, (2013) Sc(III) complexes with neutral N3- and SNS-donor ligands - a spectroscopic study of the activation of ethene polymerisation catalysts. Dalton Transactions, 42,

(6), 2213-2223. (doi:10.1039/c2dt31804k) 
Insights in the Mechanism of Selective Olefin Oligomerisation Catalysis using Stopped-Flow Freeze-Quench Techniques: a Mo K edge QEXAFS Study

Authors Stuart A. Bartlett, ${ }^{1}$ Peter P. Wells, ${ }^{1}$ Maarten Nachtegaal, ${ }^{2}$ Andrew J. Dent, ${ }^{3}$ Giannantonio Cibin, ${ }^{3}$ Gillian Reid, ${ }^{1}$ John Evans, ${ }^{1}$ Moniek Tromp ${ }^{4, *}$

Affiliations ${ }^{1}$ School of Chemistry, University of Southampton, Highfield, Southampton, SO17 1BJ, United Kingdom; ${ }^{2}$ Swiss Light Source, Paul Scherrer Institut, 5232 Villigen, Switzerland; ${ }^{3}$ Diamond Light Source Ltd, Didcot, OX11 ODE, United Kingdom; ${ }^{4}$ Strukturanalytik in der Katalyse, Chemie, Catalysis Research Centre, Technische Universität München, Lichtenbergstrasse 4, 85748 Garching, Germany, Tel. +49-89-28912813, Fax. +4989-28912866, moniek.tromp@tum.de

\section{REFEREE SUGGESTIONS}

- Prof. Dr. G. van Koten, Utrecht University, PO Box 3508 TB Utrecht, The Netherlands, g.vankoten@chem.uu.nl (homogeneous catalysis and organometallic chemistry)

- Prof. Dr. D. Cole-Hamilton, School of Chemistry, University of St Andrews, North Haugh, St Andrews, Scotland KY16 9ST, djc@st-and.ac.uk (Applications of organometallic compounds in homogeneous catalysis and materials science) 
Insights in the Mechanism of Selective Olefin Oligomerisation Catalysis using Stopped-Flow Freeze-Quench Techniques: a Mo K edge QEXAFS Study

Authors Stuart A. Bartlett, ${ }^{1}$ Peter P. Wells, ${ }^{1}$ Maarten Nachtegaal, ${ }^{2}$ Andrew J. Dent, ${ }^{3}$ Giannantonio Cibin, ${ }^{3}$ Gillian Reid, ${ }^{1}$ John Evans, ${ }^{1}$ Moniek Tromp ${ }^{4, *}$

Affiliations ${ }^{1}$ School of Chemistry, University of Southampton, Highfield, Southampton, SO17 1BJ, United Kingdom; 'Swiss Light Source, Paul Scherrer Institut, 5232 Villigen, Switzerland; ${ }^{3}$ Diamond Light Source Ltd, Didcot, OX11 ODE, United Kingdom; ${ }^{4}$ Strukturanalytik in der Katalyse, Chemie, Catalysis Research Centre, Technische Universität München, Lichtenbergstrasse 4, 85748 Garching, Germany, Tel. +49-89-28912813, Fax. +4989-28912866, moniek.tromp@tum.de

GRAPHICAL ABSTRACT
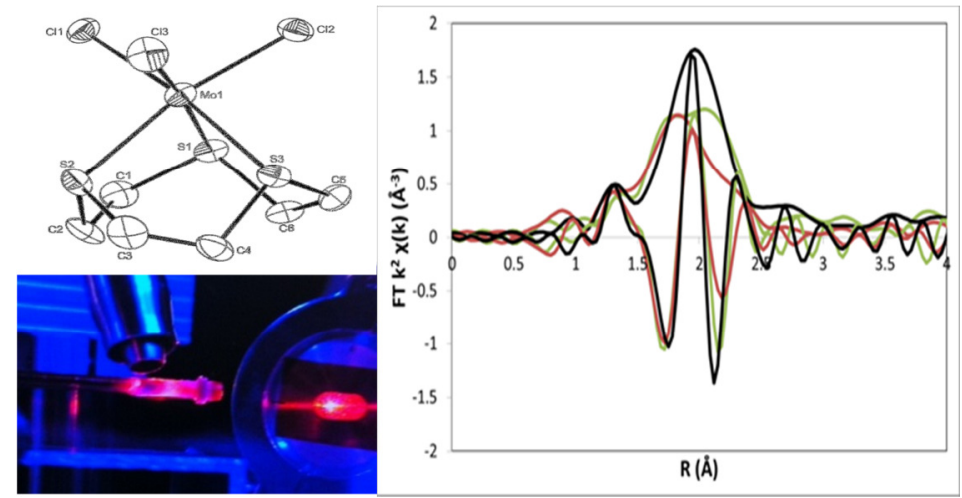

Time-resolved stopped flow XAS in combination with a novel freezequench approach have established the stepwise alkylation of $\left[\operatorname{MoX}_{3}(L)\right]$ complexes, analogous to the industrial $\left[\mathrm{CrX}_{3}(\mathrm{~L})\right]$ complexes for selective alkene oligomerisation reactions. 
Insights in the Mechanism of Selective Olefin Oligomerisation Catalysis using Stopped-Flow Freeze-Quench Techniques: a Mo K edge QEXAFS Study

Authors Stuart A. Bartlett, ${ }^{1}$ Peter P. Wells, ${ }^{1}$ Maarten Nachtegaal, ${ }^{2}$ Andrew J. Dent, ${ }^{3}$ Giannantonio Cibin, ${ }^{3}$ Gillian Reid, ${ }^{1}$ John Evans, ${ }^{1}$ Moniek Tromp ${ }^{4, *}$

Affiliations ${ }^{1}$ School of Chemistry, University of Southampton, Highfield, Southampton, S017 1BJ, United Kingdom; ${ }^{2}$ Swiss Light Source, Paul Scherrer Institut, 5232 Villigen, Switzerland; ${ }^{3}$ Diamond Light Source Ltd, Didcot, OX11 ODE, United Kingdom; ${ }^{4}$ Strukturanalytik in der Katalyse, Chemie, Catalysis Research Centre, Technische Universität München, Lichtenbergstrasse 4, 85748 Garching, Germany, Tel. +49-89-28912813, Fax. +4989-28912866, moniek.tromp@tum.de

\section{HIGHLIGHTS}

- Investigate activation of homogeneous catalysts for selective oligomerisation.

- Time-resolved and newly developed freeze-quench stopped flow XAS studies.

- Stepwise displacement of halide observed, forming $\left[\mathrm{Mo}\left(\mathrm{CH}_{3}\right)_{3}(\mathrm{~L})\right]$, without Mo dimers.

- Reaction kinetics depending on metal and halide.

- Decomposition of activated species to Mo precipitate. 
Insights in the Mechanism of Selective Olefin Oligomerisation Catalysis using Stopped-Flow Freeze-Quench Techniques: a Mo K edge QEXAFS Study

Authors Stuart A. Bartlett, ${ }^{1}$ Peter P. Wells, ${ }^{1}$ Maarten Nachtegaal, ${ }^{2}$ Andrew J. Dent, ${ }^{3}$ Giannantonio Cibin, ${ }^{3}$ Gillian Reid, ${ }^{1}$ John Evans, ${ }^{1}$ Moniek Tromp ${ }^{4, *}$

Affiliations ${ }^{1}$ School of Chemistry, University of Southampton, Highfield, Southampton, SO17 1BJ, United Kingdom; ${ }^{2}$ Swiss Light Source, Paul Scherrer Institut, 5232 Villigen, Switzerland; ${ }^{3}$ Diamond Light Source Ltd, Didcot, OX11 ODE, United Kingdom; ${ }^{4}$ Strukturanalytik in der Katalyse, Chemie, Catalysis Research Centre, Technische Universität München, Lichtenbergstrasse 4, 85748 Garching, Germany, Tel. +49-89-28912813, Fax. +4989-28912866, moniek.tromp@tum.de

\section{Abstract}

The activation of $\left[\mathrm{MoX}_{3}(\mathrm{~L})\right]$ (with $\mathrm{X}=\mathrm{Cl}, \mathrm{Br} ; \mathrm{L}=$ tridentate ligands with $\mathrm{S}_{3}$ and SNS donor sets) by $\mathrm{AlMe}_{3}$, analogous to the industrially important $\left[\mathrm{CrCl}_{3}(\mathrm{~L})\right]$ catalysts for selective oligomerisation of alkenes, has been investigated by Mo K-edge X-ray absorption (XAS) and UV-visible spectroscopies. Time-resolved stopped flow XAS, in combination with a newly developed freeze-quench approach, have established the complete alkylation of the Mo centres and a slower, stepwise sequence for $\left[\mathrm{MoBr}_{3}(\mathrm{~L})\right]$. No evidence for directly bonded or bridged Mo-Mo dimers was observed. Decomposition of the complexes in time resulted in precipitation of particulate Mo. The novel freeze-quench approach, which can trap reaction solutions within 1 second of mixing, opens up a large field of homogeneous catalysis and liquid chemistry to be studied, being able to quench at sub second time scales, while characterisation techniques with long data acquisition can be performed. 
Keywords Oligomerisation, Catalysis, XAS, Mechanism, Mo, Stopped-flow, Freeze-Quench, Homogeneous

\section{Introduction}

The efficient catalytic conversion of small molecules into more complex species in commercial demand continues to be a very important feature of the global chemical industry, and the ability to increase the specificity and selectivity of these processes is essential for clean, energy efficient processes. Oligomerisation of alkenes usually occurs via transition metal or aluminium catalysed processes to produce mixtures of alkenes in the $\mathrm{C}_{4^{-}}$ $\mathrm{C}_{26}$ range. $^{1,2}$ However, the selective trimerisation and tetramerisation of ethene to produce the linear alpha-olefins (LAOs) 1-hexene and 1-octene respectively are of major significance due to the importance of these co-monomers in the production of linear low-density polyethylene (LLDPE). ${ }^{2,3,4}$ LLDPE accounts for around $50 \%$ of the LAO co-monomers produced industrially. A variety of transition metal catalysts facilitate the selective trimerisation of ethene, most of which are based on early transition metals such as titanium, tantalum or, most importantly, chromium. ${ }^{2,3,4}$ These form the basis of several key industrial catalysts, including the Phillips pyrrolide system, the Sasol mixed heteroatom systems and the BP diphosphine systems. ${ }^{5,6,7}$

The extremely high selectivity for 1-hexene is thought to occur via a mechanism based upon a metallocyclic intermediate formed through reaction of $\mathrm{Cr}(\mathrm{III})$ pre-catalysts with ethene in the presence of methylaluminoxane (MAO) co-catalyst., ${ }^{2,6}$ The auxiliary ligand on $\mathrm{Cr}(\mathrm{III})$ is generally a tridentate ligand incorporating Group 15 or 16 donor atoms, e.g. $\left[\mathrm{CrCl}_{3}(\mathrm{SNS})\right]$ (SNS $\left.=\mathrm{RS}\left(\mathrm{CH}_{2}\right)_{2} \mathrm{NH}\left(\mathrm{CH}_{2}\right)_{2} \mathrm{SR}\right)$ and $\left[\mathrm{CrCl}_{3}\left\{\mathrm{R}_{2} \mathrm{P}\left(\mathrm{CH}_{2}\right)_{2} \mathrm{NH}\left(\mathrm{CH}_{2}\right)_{2} \mathrm{PR}_{2}\right\}\right]$ ( $\mathrm{R}=$ long chain alkyl group). Chromium complexes containing the ligand $\mathrm{Ph}_{2} \mathrm{PN}(\mathrm{iPr}) \mathrm{PPh}_{2}$ (PNP) are highly selective 
catalyst precursors for the tetramerisation of ethylene to 1-octene when activated with MAO, and improved activities are achieved when aluminate or BARF activators are introduced. ${ }^{8,9,10}$ The pursuit of catalysts with ever higher specificities and selectivities for these oligomerisations and polymerisations demands a detailed understanding of the individual stages of the catalytic cycle, the dependence upon metal, promoter and/or cocatalyst. However, developing such catalyst systems is hindered by characterisation difficulties due to the paramagnetism of the majority of the $\mathrm{Cr}$ complexes (precluding NMR analysis), and since MAO is not a single chemical entity, therefore its precise role is difficult to establish. The role of the ligand donor types (hard vs. soft) and architectures are undoubtedly very important in defining the mechanisms in these processes, promoting different reaction pathways. Further, while $\mathrm{Cr}$ complexes with softer $\mathrm{P} / \mathrm{S}$ donor atoms tend to lead to trimer/tetramer, the use of harder donor ligands only (e.g. amines) favours a Shultz-Flory distribution of oligomers. ${ }^{2}$

Work on the industrially important $\left[\mathrm{CrCl}_{3}(\mathrm{SNS})\right]$ with various alkylating agents by Gambarotta and co-workers suggests that at low $\mathrm{Cr}$ :Al ratios $\mathrm{Cl}$-bridged dimers are formed, including $\left[\{(\mathrm{SNS}) \mathrm{CrMe}\}_{2}(\mu-\mathrm{Cl})_{2}\right]^{2+},{ }^{11}$ although it is important to note that the ratio of Cr:MMAO in the operating catalyst system is very significantly higher.

Previously, we have examined a range of $\mathrm{Cr}$ (III) complexes with various neutral tridentate $\mathrm{N}$-, S- and O-donor ligands comprised of three distinct architectures: facultative $\left(\mathrm{S}_{2} \mathrm{CH}_{2} \mathrm{CH}_{2} \mathrm{SC}_{10} \mathrm{H}_{21}\right)_{2}$ and $\left.\mathrm{O}\left(\mathrm{CH}_{2} \mathrm{CH}_{2} \mathrm{SC}_{10} \mathrm{H}_{21}\right)_{2}\right)$, tripodal $\left(\mathrm{MeC}\left(\mathrm{CH}_{2} \mathrm{SC}_{4} \mathrm{H}_{9}\right)_{3}, \mathrm{MeC}\left(\mathrm{CH}_{2} \mathrm{SC}_{10} \mathrm{H}_{21}\right)_{3}\right)$ and macrocyclic $\left(\mathrm{C}_{10} \mathrm{H}_{21}\right.$ [9] ane $\mathrm{N}_{3},\left(\mathrm{C}_{10} \mathrm{H}_{21}\right)_{3}$ [9]ane $\mathrm{N}_{3}$; [9] ane $\mathrm{N}_{3}=1,4,7$-triazacyclononane $)$ as catalysts for olefin oligomerisation and polymerisation, and probed the identity of the species before and after addition of the molecular alkylating agent, $\mathrm{AlMe}_{3}$, using IR, UV/visible and EPR spectroscopy along with X-ray Absorption Fine Structure (XAFS) studies. ${ }^{12}$ 
Treatment of these compounds with excess (300 mol. equivs.) modified MAO (MMAO) leads to catalytically active species and shows significant dependence upon the ligand donor set. UV/visible and EPR measurements suggest that a change in the oxidation state of the chromium metal centre occurs in all these examples upon addition of excess $\mathrm{AlMe}_{3}$, lending support to the proposal that the catalysis involves a $\mathrm{Cr}(\mathrm{II}) / \mathrm{Cr}(\mathrm{IV})$ redox cycle. The partial structures of the $\mathrm{AlMe}_{3}$-activated species were probed via XAFS spectroscopy. It appears that when the $\mathrm{Cr}(\mathrm{III})$ complexes are treated with $\mathrm{AlMe}_{3}$, the $\mathrm{Cl}$ ligands are substituted by methyl groups and ligands $L_{1}-L_{4}$ substantially dissociate from the metal centre; with the resulting species catalysing the oligomerisation and polymerisation of ethylene.

While these are the first XAFS studies probing the activation of the Cr-based oligomerisation/polymerisation pre-catalysts, the timescale for the measurements (usually 2 to 4 hours to acquire sufficient data from $\sim 5 \mathrm{mM}$ solutions - corresponding to the approximate $\mathrm{Cr}$ concentration in the operating catalyst - for partial structure analysis) mean that, by definition, these are 'end-state' investigations. The information that can be obtained from such measurements provides limited insight into the active species given that under the operating conditions the catalyst life-time is typically $<1$ hour.

XAS (in energy dispersive mode (EDE)) was for the first time successfully synchronised with a stopped flow experiment in 1990, in which the oxidation of Fe ${ }^{\text {III }}$ aq by hydroquinone was investigated. ${ }^{13}$ More recently, stopped flow systems have been developed for homogeneous catalysis studies, to probe homogeneous catalytic intermediates in situ and time-resolved (milliseconds). ${ }^{14,15,16}$ In the stopped flow system the evolution of the reaction mixture can be monitored in time with EDE or Quick-XAS (QEXAFS), allowing full EXAFS spectra to be obtained in the millisecond to second time-scale. ${ }^{17}$ The problem with this set-up is that the energy dispersive XAFS data acquisition (but also the QEXAFS if the high time-resolution 
wants to be achieved) is performed in transmission geometry and therefore a relatively high concentration of the species under investigation is required. At the same time, the complete reaction mixture, i.e. including solvents and reagents, should not be too absorbing at the Xray energies required for the experiment. The stopped-flow EDE method has been proven for homogeneous $\mathrm{Pd}^{14}$ and $\mathrm{Re}^{18}$ systems with a high energy Pd K- and Re L-edge, enabling the in situ transmission experiments. However, although the method has been proven for homogeneous $\mathrm{Ni}(8.333 \mathrm{keV})^{14}$ and $\mathrm{Cu}(8.979 \mathrm{keV})^{16}$ systems, the $\mathrm{Cr}$ K-edge is at an even lower energy of $5.989 \mathrm{keV}$. Not only the solvent and reactant molecules, but even a few $\mathrm{cm}$ of air, are highly absorbing at these energies, severely hampering the transmission experiment.

We have pursued two methods to allow easier characterization of these catalytic systems: (i) substituting the $\mathrm{Cr}(\mathrm{III})$ for the heavier $4 \mathrm{~d} \mathrm{Mo}(\mathrm{III})$ organometallic systems to model the early stages of the activation, and (ii) modification of the stopped flow system in order to maintain the advantages of the time resolution of the instrument, but also trapping the intermediates to allow long data acquisition via XAS to be conducted.

$\mathrm{Mo}(\mathrm{III})$ complexes: We have prepared the analogous $\mathrm{Mo}(\mathrm{III})$ trichloro complexes, $\left[\mathrm{MoCl}_{3}(\mathrm{~L})\right]$ ( $\mathrm{L}=\mathrm{SNS}$ and SSS-Bz) and investigated their utility as stoichiometric model systems for the $\mathrm{Cr}$ catalysts by determining their reactivities with $\mathrm{MMAO} /$ ethylene. $\left[\mathrm{MoCl}_{3}(\mathrm{SNS}-\mathrm{R})\right]$ complexes for a variety of $\mathrm{R}$ groups have been reported previously, although they show negligible catalytic activity towards ethene oligomerisation. ${ }^{19}$ However, it is reasonable that the Mo systems might undergo similar chemistry in the early stages of activation, the slower kinetics at Mo will aid identification of individual species in the reaction. Furthermore, the Mo systems are also chosen as model systems because of the higher Mo K edge energy at which the X-ray experiment can be undertaken and thus the increased time-resolution of the XAS 
experiment to be obtained. Mo will allow time-resolved transmission studies in which real reaction intermediates are likely to be probed instead of the final (often decomposed) endstates of the $\mathrm{Cr}$ systems. With the Mo K-edge being present in the similar high energy range of $\mathrm{Pd}$ (i.e. $\sim 20 \mathrm{keV})^{14}$ the potential of the stopped-flow EDE approach for these systems is high. In a further modification, the $\left[\mathrm{MoBr}_{3}(\mathrm{~L})\right]$ analogues were also synthesised in order to aid distinction between the $S$ of the ligand and the halide in the EXAFS analyses, which is not possible for $\mathrm{S}$ and $\mathrm{Cl}$ since they are corresponding neighbours in the periodic table with similar backscattering amplitudes.

Stopped-flow XAS development: In order to overcome the inherent obstacles associated with stopped flow XAS studies, as mentioned, and to allow accurate characterisation of reaction intermediates, a XAFS cell which allows 'trapping' (stabilization) of the intermediate species present at various stages of activation and catalysis reaction, by rapid quenching of the catalyst system is required. With the catalytic intermediate 'trapped', XAFS experimentation can subsequently be performed in fluorescence mode with long data acquisition times as required for low energy systems like $\mathrm{Cr}$. The development of such a XAFS quench cell to allow highly reactive transients to be trapped on a sub-second time-scale and analysed structurally and electronically will be complementary to the established stopped-flow EDE procedure, allowing in principle the in-depth study of any homogeneous process. This approach will provide detailed structural and electronic insights in homogeneous (catalytic) reaction mechanisms.

Here, we report on the Mo(III) organometallic complexes and their activation with $\mathrm{AlMe}_{3}$, as well as a special quench-freeze XAFS cell designed to allow detailed XAFS and XANES studies to be performed to probe the early stages of activation and catalysis and thus provide a more detailed understanding of the activation stages of the polymerization and 
oligomerisation catalyst systems rather than end-state studies. The results are shown for Mo systems, and their analogy to the $\mathrm{Cr}$ is made.

\section{Experimental}

\subsection{Mo complex synthesis and characterisation}

Details of the preparation and characterisation of all the Mo(III) chloride and bromide complexes are presented in the Electronic Supplementary Data, together with crystal structure determinations for the model compounds [ $\left.\left.\mathrm{MoCl}_{3}{ }^{\mathrm{t}}{ }^{\mathrm{BuS}}\left(\mathrm{CH}_{2}\right)_{2} \mathrm{NH}\left(\mathrm{CH}_{2}\right)_{2} \mathrm{~S}^{\mathrm{t}} \mathrm{Bu}\right)\right]$ and $\left[\mathrm{MoCl}_{3}\left([9] \mathrm{aneS}_{3}\right)\right]\left([9] \mathrm{aneS}_{3}=1,4,7\right.$-trithiacyclononane).

\subsection{XAFS cell development}

We have developed a freeze quench (FQ) XAFS cell to permit measurements to be made following rapid quenching of the catalyst mixture. This is essential in order to be able to probe the early stages of activation and catalysis in the true trimerisation and tetramerisation mixtures and to provide a more detailed understanding of individual stages of the cycle(s). The stopped-flow system has a proven performance in controlled and reproducible injection of accurate mixtures in millisecond time scales. Therefore, the set-up as developed here is based on the stopped-flow EDE approach, using a commercially available stopped-flow system with a proven performance for combined EDE/UV-Vis experimentation. ${ }^{14,16}$

The stopped-flow (SFM400/QS, Biologic, France) consists of four syringes which can be filled with reaction solution or solvent. ${ }^{16,20}$ The system is computer controlled and allows injection of very precise volumes with controlled injection rates (and thus injection times). The solutions are injected using stepper motors via the delay lines and the mixers into a cuvette or capillary, depending on the requirement. Specially designed quartz cuvettes allow time- 
resolved EDE experiments to be performed on the injected mixtures. Using cuvettes with two transmission pathways perpendicular to each other will allow the addition of a complementary technique, like UV-vis, to be performed simultaneously. ${ }^{16}$ An optical fibre UV-vis spectrometer (MCS-UV-VIS-NIR 1/500-3 Fast Diode Array Detector, BioLogic, France), specially customised for the stopped flow, is also used in this study. The UV-Vis technique is used to perform time-resolved UV-vis studies (in the laboratory) as well as combined EDE/UV-Vis experiments (at the synchrotron). Due to the air and moisture sensitive nature of the chemistry, the entire stopped flow is connected to a Schlenk line allowing us to work under an argon atmosphere. To ensure the stopped flow is completely air and moisture free, a careful cleaning and passivating procedure is employed before every experiment. The internal components of the stopped-flow instrument were manufactured in $\mathrm{KelF}^{\circledR}$ (polychlorotrifluorethyene), with Kalrez ${ }^{\circledR}$ (perfluoroelastomer) rings, to ensure full chemical compatibility.

Here, we have developed a XAFS measurement cell with freeze-quench system to be attached to the stopped flow, Figure 1 . A Kapton ${ }^{\circledR}$ capillary is mounted into a custom holder attached to the standard BioLogic freeze-quench accessory. The holder allows direct injection into the Kapton ${ }^{\circledR}$ tube while an argon gas is flow around the spray exit and tube inlet and prevents ingress of air (or moisture) into the sample. The Kapton ${ }^{\circledR}$ tube is sealed with a plug, and immersed into liquid nitrogen in a Dewar (before and during injection). As such the reaction mixture can be injected (collected) and frozen directly, and maintained at $77 \mathrm{~K}$. The injection and freezing time was estimated to be below 1 second. Different delays in the stopped flow allow the accurate timing of reaction intermediates. For XAS experimentation the tube with frozen sample is subsequently placed into a holder in the X- 
ray beam, while being cooled continuously using a Cryostream (100 K). By setting up the appropriate cryo flow rate, ice formation on the outside of the capillary is restricted.

\section{[Figure 1 - colour]}

The total set-up thus consists of different parts which can be used independently or as an ensemble. As such, the system is very versatile and allows a broad range of experiments to be performed; reactions at variable temperatures, direct time-resolved studies or via quench-freeze methods (from any given reaction temperature) allowing long data acquisition times (also non XAS) if required.

\subsection{XAFS Experimentation}

All samples for solid state Mo K-edge EXAFS analysis were mixed with boron nitride, pressed into pellets under inert atmosphere and encapsulated in Kapton ${ }^{\circledR}$ tape. All solution data collected for Mo K-edge EXAFS were obtained from solutions made up to the stated concentrations with anhydrous toluene under inert conditions. The solution was then transferred to a dry, argon-purged and sealed liquid XAFS cell ${ }^{12}$ for analysis on the beamline. Reactions were also performed in this liquid XAFS cell by adding of the stated amount of $\mathrm{AlMe}_{3}$ (2.0 $\mathrm{M}$ in hexane) (using a syringe) directly into the XAFS cell. The solution was then analysed with Mo K edge EXAFS after ca. 5 min of reaction. In the rest of this paper, this cell is referred to as 'large solution cell' (in which we have measured reaction 'start-' and 'endstates').

All stopped-flow and freeze quench experiments were carried out using a BioLogic SFM-400 stopped-flow instrument as explained above. In stopped-flow mode, all reactions were observed in cuvette TC-100/10T with minimum dead volume of $30.2 \mu \mathrm{l}$. In time UV-vis was collected using J \& M Analytic AG MCS-UVNIR 500-3 fibre optic diode array 
spectrometer. When using the freeze quench attachment, the same setup is used (with UVvis and cuvette head removed) giving a total minimum dead volume of $19 \mu \mathrm{l}$ from mixing to ejection, freezing time in toluene less than 1 second. Prior to all reactions using the stoppedflow instrument, the whole instrument was purged with argon, maintaining a positive pressure throughout (including waste lines) by attachment to a Schlenk line. All lines were washed with anhydrous toluene, then the subsequent reactant, followed by further washing with anhydrous toluene.

The Mo K-edge XAFS measurements were performed at different synchrotrons across Europe. Solid and solution (large solution cell) experiments were performed at BM26 $(D U B B L E)^{21}$ of the European Synchrotron Radiation Facility (ESRF) in Grenoble, France. Mo Kedge XAS data were obtained using a Si(111) double crystal monochromator using ionisation chambers for transmission detection, with acquisition times of 30 minutes (three scans were averaged to improve $\mathrm{S} / \mathrm{N}$ unless stated otherwise). Solid and solution (large cell) step-scan experiments, as well as time-resolved stopped-flow QEXAFS/UV-Vis and 'On-the-fly'/UV-Vis were performed at the SuperXAS beamline at the Swiss Light Source in Villigen, Switzerland. Step-scans were performed using a Si(311) double crystal monochromator, while QEXAFS and 'On-the-fly' data were obtained using a channel cut Si(111) Frahm QEXAFS monochromator ${ }^{22}$. All data were obtained in transmission mode using ionisation chambers. Mo K-edge QEXAFS data were obtained at $1 \mathrm{~Hz}$ (data quality only sufficient for XANES observations, not for EXAFS analyses). Mo K-edge 'on-the-fly' XAS experiments were obtained with a time resolution of 1 minute/spectrum for the stopped-flow and 3 minutes/spectrum for the large solution cell studies. Step-scans were obtained in 35 minutes on the solids only. Time resolved QEXAFS/UV-vis as well as freeze-quench experiments were performed at the B18 beamline ${ }^{23}$ at Diamond Light Source in Didcot, England. A Si(111) 
double crystal was used in combination with ion chamber detectors for time-resolved transmission data and an Ortec $^{\circledR}$ Ge 9 element Solid State detector for fluorescence acquisition on the frozen samples. Mo K-edge step-scans were obtained in 35 minutes, whereas the QEXAFS data was obtained with a time resolution of 30 seconds. All spectra were calibrated using a Mo foil. XAS data processing and EXAFS analysis were performed using IFEFFIT ${ }^{24}$ with the Horae package ${ }^{25}$ (Athena and Artemis). The amplitude, i.e. $\mathrm{s}_{0}{ }^{2}$, was derived from EXAFS data analysis of known Mo reference compounds to be 0.85 , which was used as a fixed input parameter in all fits to allow coordination number (CN) refinement.

\section{Results and Discussion}

\subsection{Solid state and solution complexes}

A series of Mo(III) complexes was successfully synthesized and characterized:

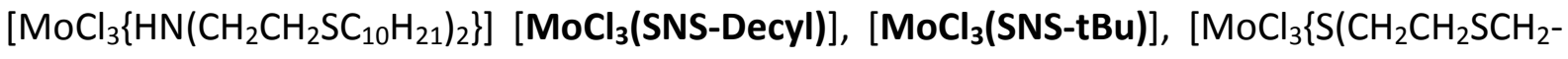

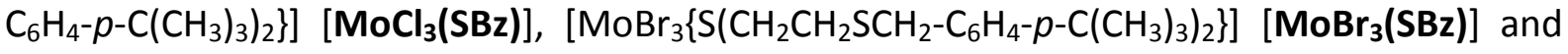
$\left[\mathrm{MoCl}_{3}\left([9] \mathrm{aneS}_{3}\right)\right] ;[9] \mathrm{aneS}_{3}=1,4,7$-trithiacyclononane (see ESI).

The solid and solution structures of the complexes were confirmed by EXAFS and compared to the other characterization obtained. The Mo $\mathrm{K}$ edge EXAFS results of the chloride complexes $\left[\mathbf{M o C l}_{3}\left(\mathbf{S N S}-\right.\right.$ Decyl)] and $\left[\mathbf{M o C l}_{3}(\mathbf{S B z})\right]$ are presented in Tables 1 and 2 , and the Mo K-edge EXAFS results on the bromide analogue $\left[\mathrm{MoBr}_{3}(\mathrm{SBz})\right]$ in Table 3. Good fits have been obtained for all data sets, with low R-factors. Representative EXAFS data and fits are presented in Figure 2, for $\left[\mathrm{MoBr}_{3}(\mathrm{SBz})\right]$ solid and solution. Some parameters with higher errors or Debye Waller factors are obtained and discussed when they appear. 
[Figure 2 - colour]

The $\operatorname{mer}$-[MoCl (SNS-Decyl)] complex was characterized by three chlorine atoms at $2.41(3)$ $\AA$, two sulfurs at $2.50(2) \AA$ and one nitrogen atom at $\sim 2.1(1) \AA$. The crystal structure data of the tBu-analogue, mer-[MoCl$(\mathbf{S N S}-\mathbf{t B u})]$, was used as an input model for the fit. The contribution of the nitrogen atom directly bonded to the Mo is very weak and difficult to identify, with a large error in distance and a large Debye Waller factor, due to the presence of the 5 higher $Z$ sulfur and chlorine atoms. The contribution can be omitted and a good fit is obtained, however, crystal structure data (Mo-N 2.208(12) Å based on XRD - see ESI) on the $\left[\mathrm{MoCl}_{3}(\mathrm{SNS}-\mathrm{tBu})\right]$ and IR results $\left(\mathrm{via} \mathrm{V}_{\mathrm{NH}}\right)$ confirm its presence and thus a fixed coordination of one Mo-N is included in the fits. Because of the proximity of chlorine and sulfur in the periodic table, they cannot be distinguished based on EXAFS only. Their different assignment here was done based on chemical knowledge on these compounds. The coordination numbers were fixed to simplify the fit and allow us to distinguish between the two shells.

The Mo-Cl distance of $2.41 \AA$ corresponds well with an average of the three distances as observed in the $\left[\mathrm{MoCl}_{3}(\mathrm{SNS}-\mathrm{tBu})\right]$ crystal structure (Mo-Cl 2.384(4), 2.410(4), 2.452(4)). The Mo-S distance as detected corresponds well to XRD (Mo-S 2.521(4), 2.532(4)). The $\left[\mathrm{MoCl}_{3}(\right.$ SNS-Decyl)] complex was subsequently dissolved in toluene and characterized with Mo K-edge EXAFS. As can be seen in Table 1, the results are similar to the solid state structure, as expected. Good fits have been obtained for solid state and solution, with low Rfactors.

The solid state structure for the $\left[\mathrm{MoCl}_{3}(\mathrm{SBz})\right]$ complex was characterised with Mo K-edge EXAFS and its results presented in Table 2 . The crystal structure of the $\left[\mathrm{MoCl}_{3}\left([9] \mathrm{9ne} \mathrm{S}_{3}\right)\right]$ (see ESI) model compound was used as an input model for the fitting procedure. The 
structure of the $\left[\mathrm{MoCl}_{3}(\mathrm{SBz})\right]$ complex could be refined with three chlorine atoms at $2.40(2)$ $\AA$ and three sulfur at $2.43(2) \AA$, with low Debye Waller factors. The two shell analysis is consistent with a facial geometry as observed in the single crystal XRD for the $\left[\mathrm{MoBr}_{3}(\mathbf{S B z})\right]$ (vide infra). The obtained distances are in the range expected Mo-Cl 2.345(2), 2.385(2),

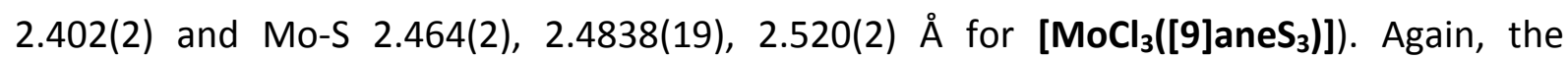
structure in solution is similar to the solid state structure, as expected.

Table 3 presents the Mo K-edge EXAFS analyses results of the bromide analogue, i.e. $\left[\mathrm{MoBr}_{3}(\mathrm{SBz})\right]$. Two shells can be refined for the solid state structure; one Mo-Br shell with a coordination number 2.5(9) and a distance of 2.54(2) $\AA$ and a low Debye Waller factor, and a second shell with 3.5(9) sulfur atoms at 2.45(6) Å with a large Debye Waller factor $(0.010(6))$. While crystallographic data collected on a poorly diffracting crystal of [ $\left.\mathrm{MoBr}_{3}(\mathrm{SBz})\right]$ was not of sufficient quality for an accurate structure determination, it did establish that the complex adopts the fac-isomer. The fac assignment is also consistent with observations on $\mathrm{Cr}(\mathrm{III})$ and other transition metal complexes with ligands containing $-\mathrm{SCH}_{2} \mathrm{CH}_{2} \mathrm{SCH}_{2} \mathrm{CH}_{2} \mathrm{~S}$ - linkages. ${ }^{26}$ With $\mathrm{Br}$ being a stronger scatterer the shell with three Mo-Br contributions strongly dictates the overall fit. The Mo-S shell is less well defined, indicating a possible distribution of Mo-S distances in the solid state structure, despite the facial geometry. The solution structure however, seems much better defined with a similar refined structure, but now with low Debye Waller factors for both shells. Because of the somewhat lower data quality, the coordination numbers were fixed input parameters.

With the complex solutions being the starting points associated with activation of the complexes for any of the reactions to be discussed in the next part, either in the large solution large solution cell or the stopped flow, the solution EXAFS data at the start of any 
reaction in the cell or the stopped flow cuvette were obtained and analyzed. All solution structures were identical, independent of the observation cell.

[Tables 1, 2, 3]

\section{2. 'End State' Analyses}

The so-called end-states of the reactions, i.e. Mo(III) complex activated with $\mathrm{AlMe}_{3}$, were characterized in the large solution cells. The reactions were performed in this cell by injecting the required amount of $\mathrm{AlMe}_{3}$ (solution in hexane or toluene) to the complex in toluene solution. The EXAFS data acquisition for all these systems starts about 5 minutes after injecting the $\mathrm{AlMe}_{3}$, with an overall acquisition time of 35 minutes. The reactions were also followed with on-the-fly XAS, acquisition of one spectrum per minute, and no further changes were observed in this period of time (5-35 minutes) in this cell. This indicates that a true reaction-end-state has been reached and measured. At longer time-scales (> $1.5 \mathrm{~h}$ ), a clear precipitation of Mo metal could be observed for all mixtures, indicating a second, irreversible, reaction taking place.

The EXAFS analyses results of the reaction end points are again represented in Table 1-3. The $\left[\mathrm{MoCl}_{3}\right.$ (SNS-Decyl)] complex was reacted with 20 equivalents of AIMe 3 . The EXAFS data can be refined to two shells, i.e. a contribution of 3(1) N/C neighbours at 2.22(9) $\AA$ and a Mo-S shell of $1.9(9)$ sulfurs at 2.50 (3) $\AA$. As with the solid state structure and solution, the Mo-N/C contribution is difficult to determine and has the highest inaccuracy (large error on coordination number and distance, with a large Debye Waller factor). The Mo-S shell is well defined. However, between the solution before reaction and after (i.e. end-state), a clear decrease in overall intensity in EXAFS can be observed which corresponds to the loss in chlorine ligands. The SNS ligand remains intact, which is confirmed by the presence of the 
Mo-S coordination at a distance similar to the solution structure, and the presence of a Mo$\mathrm{N} / \mathrm{C}$ coordination. The increase in Mo-N/C coordination number can be attributed to the replacement of the chloride ligands by methyl groups of the $\mathrm{AlMe}_{3}$. The coordination number is not very well defined $3 \pm 1$, but to achieve a full coordination sphere around the Mo, a [Mo( $\left.\mathrm{CH}_{3}\right)_{3}(\mathrm{SNS}-$ Decyl)] complex is likely to be formed, with one neighbour being the $\mathrm{N}$ atom of the SNS ligand and three more neighbours corresponding to carbon from the $\mathrm{AlMe}_{3}$ moiety. This 'activated' Mo structure is in agreement with analogous $\left[\mathrm{CrCl}_{3}(\mathrm{~L})\right]$ complexes upon activation with $\mathrm{AlMe}_{3}{ }^{12}$

Activation of $\left[\mathrm{MoCl}_{3}(\mathrm{SBz})\right]$ with 20 equivalents of $\mathrm{AlMe}_{3}$ (Figure 3) leads to a similar endstate-structure $\left[\mathrm{Mo}\left(\mathrm{CH}_{3}\right)_{3}(\mathrm{SBz})\right]$ with 3 sulfur atoms at $2.55(1) \AA$ and 3 carbon atoms at 2.23(1) $\AA$, indicating the ligand remain intact and associated to the metal (40 min of reaction), whereas the chlorine is replaced by carbon (i.e. methyl groups). In this case a very good fit with low error and Debye Waller factors for both shells is obtained, now dealing with just one type of $S$ and one type of $C$ neighbor. The Mo-S distance is slightly longer compared to the structure before reaction, consistent with the increases trans-influence of Me vs chloride, the former being a much stronger $\sigma$-donor.

[Figure 3 - colour]

The $\mathrm{Br}_{3}$ analogue however, shows a slightly different behaviour. Upon reacting 10 equivalents of $\mathrm{AlMe}_{3}$ with $\left[\mathrm{MoBr}_{3}(\mathrm{SBz})\right]$, no reaction at all is observed for reactions times up to $1 \mathrm{~h}$. Increasing the ratio Mo complex : $\mathrm{AlMe}_{3}$ to 1:20 (as with the complexes above), significant changes in the EXAFS are observed, but much smaller than for the tri-chloride systems. Comparing the EXAFS of the complex before and after reaction shows decrease in EXAFS intensity only in the region between $5<k<11 \AA^{-1}$, which is exactly the region where 
the Mo-Br is most significant (Mo-Br EXAFS intensity peaks around $\mathrm{k}=8$ whereas the Mo-S contribution is high at low $\mathrm{k}$ and diminishes towards higher $\mathrm{k}$ values). Refining the end-state EXAFS data leads to a good fit of two shells, one Mo-S with a coordination number of $2.8(5)$ and a Mo-Br with a coordination number of $0.8(1)$ (without a change in distances or Debye Waller factors compared to the solution structure). Upon reaction with $\mathrm{AlMe}_{3}$ the $\left[\operatorname{MoBr}_{3}(\mathbf{S B z})\right]$ complex loses its halide ligand, but at a very different time scale than the chloride analogue, i.e. the $\mathrm{X} / \mathrm{Me}$ exchange kinetics are much slower going from the chloride to the bromide ligand. The mechanism however seems comparable in that the halide is abstracted by the $\mathrm{AlMe}_{3}$ activator. The overall coordination of Mo seems too low to be realistic, but no further shell could be introduced reliably (to improve the fit significantly). Although there are small changes in EXAFS visible at low k-values, which might indicate the introduction of a light scatterer $(C / N)$, the quality of the data does not allow us to fit a reliable and significant Mo-C contribution here. It is possible that the Mo-C contribution is largely disordered (high Debye Waller factor) and therefore too low to be determined under the strong Mo-S and Mo-Br scatterers. Similarly, the inclusion of a Mo-Mo contribution, in search for either a direct bonded $M o$ dimer $^{27}$ or a halide bridged dimer which has been suggested in related literature, ${ }^{28}$ was unsuccessful and not significant based on the data as obtained, but cannot be excluded completely. For all reactions, at longer times scales $>1.5$ h, the Mo K-edge XAS signal disappears completely and black precipitate is observed in the cell, indicating the formation of Mo metal (Mo-Mo contributions observed in time resolved experiment, via infra).

\subsection{Time Resolved XAS (and UV-vis)}

Time-resolved reactions were performed using the stopped-flow instrument. The timeresolved XAS experiments were performed in transmission, through the observation cuvette, 
with time-resolved UV-vis taken simultaneously, using optical fibers in transmission perpendicular to the XAS observation. Because of the different sensitivity of the two techniques, the observation path-length of the XAS was 10 times the path-length of the UVVis.

The combined time-resolved data of the reaction of $\left[\mathrm{MoCl}_{3}(\mathbf{S N S})\right]$ ( $25 \mathrm{mM}$ in toluene) with 20 equivalents of $\mathrm{AlMe}_{3}$ are displayed in Figure 4. Quick EXAFS spectra and time resolved UV Vis spectra were obtained every 20 seconds. Because of the slow progress of the reaction and to enhance the clarity of the data and its changes, only a selection of spectra is presented here.

\section{[Figure 4 - colour]}

Although the overall EXAFS data quality is much lower (as expected due to the much shorter acquisition times), the overall change in EXAFS in time is clear and similar to the end-state solution as discussed above, i.e. an overall loss in EXAFS intensity indicating a loss of ligand. It is interesting to observe that most of the changes are happening in the first 1.5 minutes, which is confirmed by the UV-visible data obtained simultaneously. The UV-visible spectra of the Mo starting complexes each show the lowest band around $22000 \mathrm{~cm}^{-1}$, attributed to the ${ }^{4} \mathrm{~A}_{2 g}$ to ${ }^{4} \mathrm{~T}_{2 \mathrm{~g}}$ transition of a $\mathrm{Mo}(\mathrm{III})$ complex in approximately $\mathrm{O}_{\mathrm{h}}$ symmetry. This corresponds to an increase in $\mathrm{Dq}$ of approximately $50 \%$ relative to the corresponding $\mathrm{Cr}$ (III) complexes, ${ }^{2,8,12,29}$ which is reasonable on the basis of their respective $4 d^{3}$ and $3 d^{3}$ configurations. Based on Jorgensen's mode ${ }^{30}$ the lowest energy charge transfer transitions are expected to occur $>30000 \mathrm{~cm}^{-1}$. Upon addition of $\mathrm{AlMe}_{3}$ the $\mathrm{d}$-d transition decreases in intensity, with concomitant appearance of new bands over a period of a few minutes (Figure 4), and then disappearance of all bands occurring around 18 minutes. The combination of 
the UV-vis measurements with the EXAFS measurements is very useful in establishing when changes in speciation occur and hence guiding when EXAFS data should be recorded. After a reaction time of 18 minutes in the stopped-flow, the Mo K-edge XAS signal as well as the UV Vis signal are lost completely, indicating the precipitation of Mo. It is interesting note that the precipitation of Mo metal is observed at much shorter timescales compared to the dropout observed in the large solution cell (18 minutes compared to $1.5 \mathrm{~h}$ ). This is probably due to the much smaller volume of the stopped flow cuvette compared to the large cell of $30 \mu \mathrm{l}$ and $3 \mathrm{ml}$ respectively. The effects of the constant beam exposure to the full reaction volume in the small cuvette, together with the larger surface area (edge corners internal cuvette) might enhance the Mo particle/colloid formation.

The reaction of $\left[\mathrm{MoCl}_{3}(\mathrm{SBz})\right]$ was performed with different ratios of $\mathrm{AlMe}_{3}$. At a $\mathrm{MoCl}_{3}(\mathrm{SBz})$ : $\mathrm{AlMe}_{3}$ ratio of 1:1, no reaction was observed. When the amount of $\mathrm{AlMe}_{3}$ was increased to 4 and 8 equivalents, changes in the EXAFS upon reaction were observed, at the same time scales. The EXAFS analysis of the 8 equivalent $\mathrm{AlMe}_{3}$ data after 4 minutes of reaction is presented in Table 2. A full displacement of the chlorine ligand by carbon is observed, as for the end state measure in the large solution cell. However, at 4 minutes already a significant proportion of Mo-Mo contributions can be detected (Figure 3, Table 2), indicating a significant amount of Mo colloid formation. Although the accuracy of the higher Mo-Mo shells is low, the Mo particles detected should be of considerable size for these shells to be visible and significant in the Fourier transforms. Again, this irreversible deactivation of the Mo is observed at much shorter time scales compared to the reactions in the large solution cell. Higher equivalents of $\mathrm{AlMe}_{3}$ led to an almost immediate Mo precipitation.

Reactions of the tri-bromide analogues were, as observed in the large solution cell, significantly slower. The $\left[\mathrm{MoBr}_{3}(\mathrm{SBz})\right]$ complex was reacted with 20 equivalents of $\mathrm{AlMe}_{3}$ 
and the EXAFS after 4 minutes of reaction was analysed and presented in Table 3 . As for the end-state analyses only a small loss in bromide ligand was observed, whereas the Bz ligand remains intact and no significant $\mathrm{Mo}-\mathrm{C}$ can be fitted reliably. The amount of $\mathrm{Mo}-\mathrm{Br}$ contributions still present is slightly higher compared to the large solution cell, which corresponds to the shorter reaction time in the stopped flow. Here, no clear effect upon reaction rate is observed going from the large volume large solution cell to the small volume stopped flow cuvette.

\subsection{Freeze-Quench $\left[\mathrm{MoBr}_{3}(\mathrm{SBz})\right]$}

The BioLogic stopped flow quench system was modified and an air and moisture tight freezequench accessory developed to allow us to use the millisecond time resolution of the stopped flow apparatus to select and isolate different intermediate, freeze-quench them and keep them frozen to allow long EXAFS experimentation to be conducted (if required). The reaction solutions are sprayed directly into a Kapton ${ }^{\circledR}$ tube immersed in liquid nitrogen. The required freezing time for the volume of $75 \mu$ is very difficult to assess and measure, but estimated to be less than $1 \mathrm{~s}$ in total. The entire system was thoroughly tested with a very air and moisture sensitive system, i.e. the green $\left(\mathrm{TiCp}_{2}\right)_{2}(\mathrm{~m}-\mathrm{Cl})_{2},{ }^{31}$ to ensure its functionality. The deep green dimeric Ti solution (in toluene) system is very sensitive to $\mathrm{O}_{2}$ and rapidly changes to yellow upon oxidation. Glove box tests showed that the solid oxidised at $\mathrm{O}_{2}$ levels $>5$ ppm. After taking the solution through the stopped flow and freezing it into the Kapton ${ }^{\circledR}$ tube, the solution remained blue, indicating a good $\mathrm{O}_{2}$ free system was established.

To validate the freeze quench approach we have investigated the reaction of $\left[\mathrm{MoBr}_{3}(\mathrm{SBz})\right]$ with 20 equivalents of $\mathrm{AlMe}_{3}$. Initially the starting Mo solution is injected in the capillary, frozen and measured. The same structural parameters were obtained as for the solution 
state structure. The reaction was then freeze-quenched after 5 seconds and 5 minutes of reaction, to compare to the time-resolved data as obtained in the stopped flow. Figure 5 shows the EXAFS data obtained for the different frozen intermediates alongside the solution starting structure. The signal to noise of the frozen data is somewhat lower compared to the time resolved data in the cuvette. This can be easily improved by acquiring more spectra and measuring longer (but this was not done here due to time constraints). In practice it turns out (above) that this reaction is rather slow, so with hindsight maybe not the best system to demonstrate the stopped flow freeze quench possibilities. However, as for the time-resolved data, a small decrease in the EXAFS, especially in the $5<k<11 \AA^{-1}$ region, in time is observed. Comparing the Fourier transforms of the three data sets shows nicely the decrease in intensity on the high $\mathrm{R}$ side, i.e. where the Mo-Br contribution is. The analyses of both data sets, as presented in Table 3, shows again the partial removal of $\mathrm{Br}$, without dissociation of the SBz ligand, which closely corresponds to the time-resolved data. Moreover, the freeze quench set-up now gives access to good quality EXAFS 5 second data, something which could not be obtained using QEXAFS (data quality of $1 \mathrm{~s} /$ spectrum QEXAFS data at SLS too low to allow EXAFS analysis, at Diamond QEXAFS data acquisition was 20-30 s/spectrum).

\section{[Figure 5 - colour]}

The combination of experiments as performed in this study clearly show the stepwise displacement of the halide ligand upon activating $\left[\mathrm{MoX}_{3}(\mathrm{~L})\right]$ complexes with $\mathrm{AlMe}_{3}$. The high Mo K-edge energy allows time-resolved stopped flow XAS experimentation down a timeresolution of $30 \mathrm{~s}$ per spectrum (for good S/N quality data to allow EXAFS analyses). The new freeze-quench methodology is an extension to the stopped flow with a freeze-quenching 
time of less than a second, thereby giving access to a time regime not accessible with QEXAFS.

Although the Mo complexes have shown a very low catalytic activity towards ethene oligomerisation, ${ }^{19}$ it is reasonable that the Mo systems undergo similar chemistry in the early stages of activation. This is in fact what we see. The stepwise displacement of the halide forming $\left[\mathrm{Mo}\left(\mathrm{CH}_{3}\right)_{3}(\mathrm{~L})\right]$ is in agreement with our previous studies on the $\mathrm{AlMe}_{3}$ activation of comparable $\left[\mathrm{CrCl}_{3}(\mathrm{~L})\right]$ complexes. ${ }^{12}$ Whereas literature reports on halide briged dimer formation at low Cr:Al ratios, ${ }^{11}$ dimeric Mo species are not observed in this study at high Mo:Al ratios, i.e. ratios more relevant to industrial conditions. ${ }^{2}$ Going from the $\mathrm{Cr}$ to the Mo analogues, a clear decrease in reaction rate was observed, as expected. However, also a significant dependence of reaction kinetics is observed upon halide ligand, with the $\left[\mathrm{MoCl}_{3}(\mathrm{~L})\right]$ being much faster than the $\left[\mathrm{MoBr}_{3}(\mathrm{~L})\right]$ analogues. It is difficult to immediately address this difference, since the exact displacement mechanism is unknown and can in fact be different for the two types of complexes. The reaction can be based upon a dissociative or Lewis acid approach, with the $\mathrm{Al}-\mathrm{Cl}$ versus $\mathrm{Al}-\mathrm{Br}$ bond formations being the rate determining steps. Moreover, at the high concentrations of reactants as used in this study, the activation reaction is in competition with the complex dissociation reaction as observed, especially for the chloride analogues. This is not necessarily a problem for the catalysis, since we are only looking at the first stage of activation here, and all subsequent catalysis reaction steps will only make the formed complexes more stable.

\section{Conclusions}

We have used time-resolved Mo K-edge EXAFS in a stopped flow system to probe the first stage of activation of the Mo analogues of the industrially important ethene trimerisation 
catalysts, and compared the results with start and end-state studies. The results demonstrate that treatment of the Mo complex solution with excess $\mathrm{AlMe}_{3}$ leads to halide loss, forming $\left[\mathrm{Mo}\left(\mathrm{CH}_{3}\right)_{3}(\mathrm{~L})\right]$, and provides strong evidence that dinuclear species with direct Mo-Mo bonds or halide-bridged dimers are not present under the conditions examined (1:20 Mo:Al). We have also developed a freeze quench attachment which takes advantage of the excellent volume and time-scale control offered by the stopped flow instrument, and allows reaction mixtures to be frozen (to liquid nitrogen temperature) within 1 second of mixing, hence allowing reactive, short-lived intermediate species to be trapped, and enabling EXAFS data collections to be conducted on these over long time-scales. The freeze quench experiment can be performed in fluorescence mode, which is essential for studying systems with low energy absorption edges (e.g. Cr, Sc etc). A key advantage is that the much longer data acquisition times associated with these $3 \mathrm{~d}$ metal systems are easily accommodated. This technique has great potential for probing reactive intermediates in many homogeneous catalytic systems. Further experiments using this approach to examine the catalytic process associated with the $\left[\mathrm{CrCl}_{3}(\mathrm{SNS})\right]$ ethene timerisation system are now planned.

\section{Acknowledgements}

The ESRF is gratefully acknowledged for provision of beamtime (26-01-829), and the staff with their help. The Swiss Light Source, PSI, Villigen, Switzerland is gratefully acknowledged for provision of beamtime under project 20090943, with EU funding under EU project FP7 ELISA. The staff at the Super-XAS beamline for their help during the beamtime. The Diamond Light Source for beamtime provision under project SP7046-1, and the beamline staff at B18 XAS beamline for their support during the beamtime. MT gratefully acknowledges the EPSRC 
(EP/E060404/1), SAB and PPW the EPSRC (EP/F032463/1). Dr. M. Webster is gratefully acknowledged for help with the X-ray crystallography.

\section{Supplementary Materials}

Synthetic methods and characterization data for all complexes. Crystal structure determinations for the $\left[\mathrm{MoCl}_{3}\left(\mathrm{SNS}^{\mathrm{t}}{ }^{\mathrm{Bu}}\right)\right]$ and $\left[\mathrm{MoCl}_{3}\left([9] \mathrm{aneS}_{3}\right)\right]$ model complexes.

\section{Captions}

Figure 1. Stopped-flow Freeze-Quench accessory: A Perspex box is constructed to be mounted to the standard spray outlet of the stopped-flow quench accessory and the hold the kapton ${ }^{\circledast}$ tube. A gas inlet and outlet provide an argon gas atmosphere from the spray exit to the tube inlet. The right picture shows the Kapton ${ }^{\circledast}$ tube, containing frozen Mo intermediate, positioned in the X-ray beam using a red laser and in a Cryostream.

Figure 2. Mo K-edge $k^{2}$-weighted EXAFS and Fourier transform data (solid lines) and fits (dotted lines) for $\left[\mathrm{MoBr}_{3}(\mathrm{SBz})\right]$ solid (black) and solution (red).

Figure 3. Fourier transforms of $\mathrm{k}^{3}$-weighted EXAFS data on $\left[\mathrm{MoCl}_{3}(\mathrm{SBz})\right]$ with $\mathrm{AlMe}_{3}$ in large solution cell (20 equivalents, $\sim 40$ minutes, red) and stopped flow (8 equivalents, $\sim 4$ minutes, green), compared to unreacted complex (black) $\left(2<k<16 \AA^{-1}\right)$.

Figure 4. Combined time resolved UV-Vis and QEXAFS data on the reaction of $\left[\mathrm{MoCl}_{3}(\mathrm{SNS})\right]$ (25 $\mathrm{mM}$ in toluene) with 20 equivalents of $\mathrm{AlMe}_{3}$.

Figure 5. Raw $k^{2}$-weighted EXAFS data (a) and Fourier Transform $(1.8<k<12)$ (b) data on the $\left[\mathrm{MoBr}_{3}(\mathrm{SBz})\right]$ solution (black), with 20 equivalents of $\mathrm{AlMe}_{3} \mathrm{FQ}$ after 5 seconds (green) and FQ after 5 minutes (red) samples.

Table 1. Mo K-edge EXAFS data analyses results on $\mathrm{MoCl}_{3}(\mathrm{SNS})$ complex (all fitted in combined $\mathrm{k}^{1-3}$ weighting). 
Table 2. Mo K-edge EXAFS data analyses results on $\mathrm{MoCl}_{3}(\mathrm{SBz})$ complex (all fitted in combined $\mathrm{k}^{1-3}$ weighting).

Table 3. Mo K-edge EXAFS data analyses results on $\mathrm{MoCl}_{3}(\mathrm{SBz})$ complex (all fitted in combined $\mathrm{k}^{1-3}$ weighting).

\section{References}

1. J. Skipinska, Chem. Rev. 91 (1991) 613.

2. D. S. McGuinness, Chem. Rev. 111 (2011) 2321 and references therein.

3. J. T. Dixon, M. J. Green, F. M. Hess, D. H. Morgan, J. Organometal. Chem. 689 (2004) 3641.

4. D. F. Wass, Dalton Trans. (2007) 816.

5. W. Janse van Rensburg, C. Grove, J. P. Steynberg, K. B. Stark, J. J. Huyser and P. J. Steynberg, Organometallics 23 (2004) 1207.

6. D.S. McGuinness, P. Wasserscheid, W. Keim, J.T. Dixon, J.J.C. Grove, C. Hu, U. Englert, Chem. Commun. (2003) 334; D.S. McGuinness, P. Wasserscheid, W. Keim, D.H. Morgan, J.T. Dixon, A. Bollmann, H. Maumela, F.M. Hess, U. Englert, J. Am. Chem. Soc. 125 (2003) 125, 5272; D. S. McGuinness, P. Wasserscheid, D. H. Morgan and J. T. Dixon, Organometallics 24 (2005) 552; D.S. McGuinness, P. Wasserscheid, W. Keim, J.T. Dixon, J.J.C. Grove, C. Hu, U. Englert, Chem. Commun. (2003) 334; D.S. McGuinness, P. Wasserscheid, W. Keim, D.H. Morgan, J.T. Dixon, A. Bollmann, H. Maumela, F.M. Hess, U. Englert, J. Am. Chem. Soc. 125 (2003) 5272.

7. A. Carter, S. A. Cohen, N. A. Cooley, A. Murphy, J. Scutt and D. F. Wass, Chem. Commun. (2002) 858.

8. D. S. McGuinness, D. B. Brown, R. P. Tooze, F. M. Hess, J. T. Dixon and A. M. Z. Slawin, Organometallics 25 (2006) 3605.

9. D. S. McGuinness, A. J. Rucklidge, R. P. Tooze and A. M. Z. Slawin, Organometallics 26 (2007) 2561.

10. A. J. Rucklidge, D. S. McGuinness, R. P. Tooze, A. M. Z. Slawin, D. A. Pelletier, M. J. Hanton and P. B. Webb, Organometallics 26 (2007) 2782.

11. C. Temple, A. Jabri, P. Crewdson, S. Gambarotta, I. Korobkov and R. Duchateau, Angew. Chem. Int. Ed. 45 (2006) 7050.

12. J. O. Moulin, J. Evans, D. S. McGuinness, G. Reid, A. J. Rucklidge, R. P. Tooze and M. Tromp, Dalton Trans. (2008) 1177.

13. N. Yoshida, T. Matsushita, S. Saigo, H. Oyanagi, H. Hashimoto, M. Fujimoto, J. Chem. Soc., Chem. Commun. (1990) 354.

14. M. B. B. Abdul Rahman, P. R. Bolton, J. Evans, A. J. Dent, I. Harvey, S. Diaz-Moreno, Faraday Discuss. 122 (2002) 211.

15. M. Tromp, J. R. A. Sietsma, J. A. van Bokhoven, G. P. F. van Strijdonck, R. J. van Haaren, A. M. J. van der Eerden, P. W. N. M. van Leeuwen, D. C. Koningsberger, Chem. Comm. (2003) 128.

16. M. Tromp, S. S. van Berkel, A. van den Hoogenband, M. C. Feiters, B. de Bruin, S. G. Fiddy, J. A. van Bokhoven, P. W. N. M. van Leeuwen, G. P. F. van Strijdonck, D. C. Koningsberger, Organometallics 29 (2010) 3085. 
17. J. Evans, A. Puig-Molina, M. Tromp, MRS Bulletin 32 (2007) 1038.

18. G. Smolentsev, G. Guilera, M. Tromp, S. Pascarelli, A. V. Soldatov, J. Chem. Phys. 130 (2009) 174508.

19. S. P. Downing, M. J. Hanton, A M. Z. Slawin and R. P. Tooze, Organometallics 28 (2009) 2417.

20. M. Tromp, 'Developments of Time-Resolved XAFS Techniques: Applications in Homogeneous Catalysis', Ph.D. Thesis, Utrecht, The Netherlands, 2004, pp 20-23.

21. S. Nikitenko, A. M. Beale, A. M. J. van der Eerden, S. D. M. Jacques, O. Leynaud, M. G. O'Brien, D. Detollenaere, R. Kaptein, B. M. Weckhuysen, W. Bras, J. Synchrotron Radiat. 15 (2008), 632-640.

22. R. Frahm, Nucl. Instrum. Methods Phys. Res. Sect. A 270 (1988) 578; R. Frahm, Rev. Sci. Instrum. 60 (1989) 2515; R. Frahm, B. Griesebock, M. Richwin, D. Ltzenkirchen-Hecht, Proc. 8th Int. Conf. Synchrotron Radiation Instumentation (San Francisco, USA) 2004, pp. 14111414; R. Frahm, B. Griesebock, D. Luetzenkirchen-Hecht, Phys.Scr. T115 (2005) 974.

23. A. J. Dent, G. Cibin, S. Ramos, A. D. Smith, S. M. Scott, L. Varandas, M. R. Pearson, N. A. Krumpa, C. P. Jones, P. E. Robbins, J. Phys.: Conf. Ser. 190 (2009) 01203.

24. M. J. Newville, J. Synchrotron Radiat. 8 (2001) 322.

25. B. Ravel, M. J. Newville, J. Synchrotron Radiat. 12 (2005) 537.

26. C. D. Beard, L. Carr, M. F. Davis, J. Evans, W. Levason, L. D. Norman, G. Reid, M. Webster, Eur. J. Inorg. Chem. (2006) 4399; G. J. Grant, K. E. Rogers, W. N. Setzer, D. G. VanDerveer, Inorg. Chim. Acta 234 (1995) 35; R.E. Wolf, J. R. Hartman, J. M. E. Storey, B. M. Foxman, S. R. Cooper, J. Am. Chem. Soc. 109 (1987) 4328.

27. F.A. Cotton, Multiple bonds between metal atoms, F. A. Cotton, C. A. Murillo, R. A. Walton, 3rd edition, Springer, 2005, ISBN 978-0-387-25084-7.

28. C. Temple, A. Jabri, P. Crewdson, S. Gambarotta, I. Korobkov, R. Duchateau, Angew. Chem. Int. Ed. 45 (2006) 7050.

29. J. O. Moulin, 'X-Ray Absorption Spectroscopy for the Study of a Homogeneous Catalysis System based upon Chromium, PhD Thesis, Southampton, United Kingdom, 2006.

30. A. B. P. Lever in Inorganic Electronic Spectroscopy (2nd Ed), Elsevier, Canada, 1984, Ch. 5. 31. S. J. Nieter Burgmayer, J. Chem. Ed. 75 (1998) 460. 
Insights in the Mechanism of Selective Olefin Oligomerisation Catalysis using Stopped-Flow Freeze-Quench Techniques: a Mo K edge QEXAFS Study

Authors Stuart A. Bartlett, ${ }^{1}$ Peter P. Wells, ${ }^{1}$ Maarten Nachtegaal, ${ }^{2}$ Andrew J. Dent, ${ }^{3}$ Giannantonio Cibin, ${ }^{3}$ Gillian Reid, ${ }^{1}$ John Evans, ${ }^{1}$ Moniek Tromp ${ }^{4, *}$

Affiliations ${ }^{1}$ School of Chemistry, University of Southampton, Highfield, Southampton, SO17 1BJ, United Kingdom; ${ }^{2}$ Swiss Light Source, Paul Scherrer Institut, 5232 Villigen, Switzerland; ${ }^{3}$ Diamond Light Source Ltd, Didcot, OX11 ODE, United Kingdom; ${ }^{4}$ Strukturanalytik in der Katalyse, Chemie, Catalysis Research Centre, Technische Universität München, Lichtenbergstrasse 4, 85748 Garching, Germany, Tel. +49-89-28912813, Fax. +4989-28912866, moniek.tromp@tum.de

\section{TABLES}




\begin{tabular}{|c|c|c|c|c|}
\hline Abs Sc & C.N. & $R(\AA)$ & $2 \sigma^{2}\left(\AA^{-2}\right)$ & Fitting parameters, $\mathrm{k}\left(\AA^{-1}\right)$ \\
\hline \multicolumn{5}{|c|}{ Solid $\left[\mathrm{MoCl}_{3}(\mathrm{SNS}-\mathrm{Decyl})\right]$} \\
\hline Mo-N & 1 (fix) & $2.1(1)$ & $0.010(6)$ & $2.0<\mathrm{k}<14.7 ; 1.1<\mathrm{R}<2.57$ \\
\hline $\mathrm{Mo}-\mathrm{Cl}(\mathrm{S})$ & 3 (fix) & $2.41(3)$ & $0.002(3)$ & $A m p=0.85 ; E_{0}=3(1) ; R=0.01$ \\
\hline Mo-S(Cl) & 2 (fix) & $2.50(2)$ & $0.001(2)$ & \\
\hline
\end{tabular}

\begin{tabular}{lllll}
\multicolumn{3}{l}{ Solution $\left[\mathrm{MoCl}_{3}\right.$ (SNS-Decyl)] } & & \\
Mo-N & 1 (fix) & $2.1(1)$ & $0.015(9)$ & $2.0<\mathrm{k}<15.7 ; 1.1<\mathrm{R}<2.7$ \\
\hline Mo-Cl(S) & 3 (fix) & $2.40(2)$ & $0.002(1)$ & $A m p=0.85 ; \mathrm{E}_{0}=3(1) ; \mathrm{R}=0.02$ \\
\hline Mo-S(Cl) & 2(fix) & $2.53(2)$ & $0.002(2)$ &
\end{tabular}

[MoCl${ }_{3}$ (SNS-Decyl)] + 20 equivalent $\mathrm{AlMe}_{3}$ - Large solution cell
$\begin{array}{lllll}\text { Mo-N/C } & 3(1) & 2.22(9) & 0.010(9) & 2.0<\mathrm{k}<11 ; 1<\mathrm{R}<3 \\ \text { Mo-S(Cl) } & 1.9(9) & 2.50(3) & 0.003(4) & \mathrm{Amp}=0.85 ; \mathrm{E}_{0}=3(3) ; \mathrm{R}=0.05\end{array}$

Table 1. Mo K-edge EXAFS data analyses results on $\mathrm{MoCl}_{3}(\mathrm{SNS})$ complex (all fitted in combined $\mathrm{k}^{1-3}{ }_{-}$ weighting). 


\begin{tabular}{|c|c|c|c|c|}
\hline Abs Sc & C.N. & $R(\AA)$ & $2 \sigma^{2}\left(\AA^{-2}\right)$ & Fitting parameters, $\mathrm{k}\left(\AA^{-1}\right)$ \\
\hline \multicolumn{5}{|c|}{ Solid $\left[\mathrm{MoCl}_{3}(\mathrm{SBz})\right]$} \\
\hline $\mathrm{Mo}-\mathrm{Cl}(\mathrm{S})$ & $2.8(3)$ & $2.40(2)$ & $0.002(2)$ & $2.0<k<16.8 ; 1<R<2.9$ \\
\hline $\mathrm{Mo}-\mathrm{S}(\mathrm{Cl})$ & $2.8(3)$ & $2.43(2)$ & $0.003(3)$ & $A m p=0.85 ; E_{0}=1(1) ; R=0.01$ \\
\hline \multicolumn{5}{|c|}{ Solution $\left[\mathrm{MoCl}_{3}(\mathrm{SBz})\right]$} \\
\hline $\mathrm{Mo}-\mathrm{Cl}(\mathrm{S})$ & $2.8(3)$ & $2.39(2)$ & $0.001(2)$ & $2.95<k<16.5 ; 1<R<3$ \\
\hline $\mathrm{Mo}-\mathrm{S}(\mathrm{Cl})$ & $2.8(3)$ & $2.46(2)$ & $0.003(3)$ & $A m p=0.85 ; E_{0}=1(1) ; R=0.02$ \\
\hline \multicolumn{5}{|c|}{$\left[\mathrm{MoCl}_{3}(\mathrm{SBz})\right]+8$ equivalent $\mathrm{AlMe}_{3}$ - Stopped-flow $\sim 4$ minutes } \\
\hline $\mathrm{Mo}-\mathrm{S}(\mathrm{Cl})$ & $2.2(9)$ & $2.55(1)$ & $0.002(1)$ & $2.0<k<14.6 ; 1<R<5.5$ \\
\hline Mo-C & $3.6(9)$ & $2.26(1)$ & $0.002(1)$ & $A m p=0.85 ; E_{0}=6(1) ; R=0.01$ \\
\hline Mo-Mo & $1.3(8)$ & $2.97(3)$ & $0.010(5)$ & \\
\hline Mo-Mo & $2(1)$ & $4.36(5)$ & $0.011(4)$ & \\
\hline Mo-Mo & $11(9)$ & $5.18(7)$ & $0.015(7)$ & \\
\hline
\end{tabular}

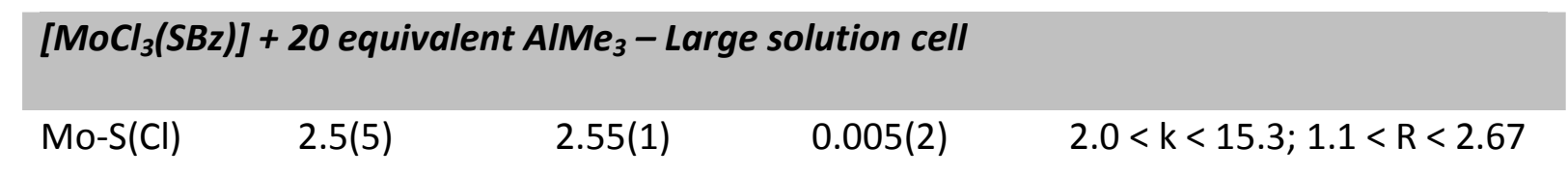

$\begin{array}{llll}\text { Mo-C 2.6(4) } 2.23(1) & 0.001(1) \quad A m p=0.85 ; E_{0}=8(1) ; R=0.03\end{array}$

Table 2. Mo K-edge EXAFS data analyses results on $\mathrm{MoCl}_{3}(\mathrm{SBz})$ complex (all fitted in combined $\mathrm{k}^{1-3}$ weighting). 


\begin{tabular}{|c|c|c|c|c|}
\hline Abs Sc & C.N. & $\mathbf{R}(\AA)$ & $2 \sigma^{2}\left(\AA^{-2}\right)$ & Fitting parameters, $k\left(\AA^{-1}\right)$ \\
\hline \multicolumn{5}{|c|}{ Solid $\left[\mathrm{MoBr}_{3}(\mathrm{SBz})\right]$} \\
\hline Mo-S & $3.5(9)$ & $2.45(6)$ & $0.010(6)$ & $1.7<\mathrm{k}<14.2 ; 1.2<\mathrm{R}<2.6$ \\
\hline $\mathrm{Mo}-\mathrm{Br}$ & $2.5(9)$ & $2.54(2)$ & $0.002(3)$ & $A m p=0.85 ; E_{0}=-4(1) ; R=0.007$ \\
\hline \multicolumn{5}{|c|}{ Solution $\left[\mathrm{MoBr}_{3}(\mathrm{SBz})\right]$} \\
\hline Mo-S & $3($ fix) & $2.45(2)$ & $0.003(1)$ & $1.8<k<13.5 ; 1.1<R<3$ \\
\hline Mo-Br & $3($ fix) & $2.55(1)$ & $0.006(1)$ & $A m p=0.85 ; E_{0}=-4(1) ; R=0.01$ \\
\hline \multicolumn{5}{|c|}{$\left[\mathrm{MoBr}_{3}(\mathrm{SBz})\right]+20$ equivalent $\mathrm{AlMe} \mathrm{M}_{3}-$ Stopped flow - after $\sim 4 \mathrm{~min}$} \\
\hline Mo-S & $2.5(3)$ & $2.45(1)$ & $0.003(1)$ & $2<\mathrm{k}<17 ; 1.1<\mathrm{R}<3$ \\
\hline $\mathrm{Mo}-\mathrm{Br}$ & $1.4(9)$ & $2.59(1)$ & $0.006(4)$ & $A m p=085 ; E_{0}=-4(1) ; R=0.01$ \\
\hline \multicolumn{5}{|c|}{$\left[\mathrm{MoBr}_{3}(\mathrm{SBz})\right]+20$ equivalent $\mathrm{AlMe}_{3}-$ Stopped flow - Freeze Quench - after $\sim 5 \mathrm{sec}$} \\
\hline Mo-S & $2.9(4)$ & $2.41(1)$ & $0.004(3)$ & $2<\mathrm{k}<14 ; 1<\mathrm{R}<3$ \\
\hline $\mathrm{Mo}-\mathrm{Br}$ & $2.4(7)$ & $2.58(1)$ & $0.005(3)$ & $A m p=0.85 ; E_{0}=-5(1), R=0.01$ \\
\hline \multicolumn{5}{|c|}{$\left[\mathrm{MoBr}_{3}(\mathrm{SBz})\right]+20$ equivalent $\mathrm{AlMe_{3 }}$ - Stopped flow - Freeze Quench - after $\sim 5 \mathrm{~min}$} \\
\hline Mo-S & $3.3(3)$ & $2.38(1)$ & $0.005(2)$ & $2<k<14 ; 1<\mathrm{R}<3$ \\
\hline $\mathrm{Mo}-\mathrm{Br}$ & $1.6(8)$ & $2.61(1)$ & $0.005(3)$ & $A m p=0.85 ; E_{0}=-5(1), R=0.01$ \\
\hline \multicolumn{5}{|c|}{$\left[\mathrm{MoBr}_{3}(\mathrm{SBz})\right]+20$ equivalent $\mathrm{AlMe} \mathrm{M}_{3}-$ Large solution cell } \\
\hline Mo-S & $2.8(5)$ & $2.43(2)$ & $0.003(2)$ & $2<k<13 ; 1<R<3$ \\
\hline Mo-Br & $0.8(1)$ & $2.61(2)$ & $0.003(7)$ & $A m p=0.85 ; E_{0}=-4(2), R=0.01$ \\
\hline
\end{tabular}

Table 3. Mo K-edge EXAFS data analyses results on $\mathrm{MoCl}_{3}(\mathrm{SBz})$ complex (all fitted in combined $\mathrm{k}^{1-3}$ weighting). 

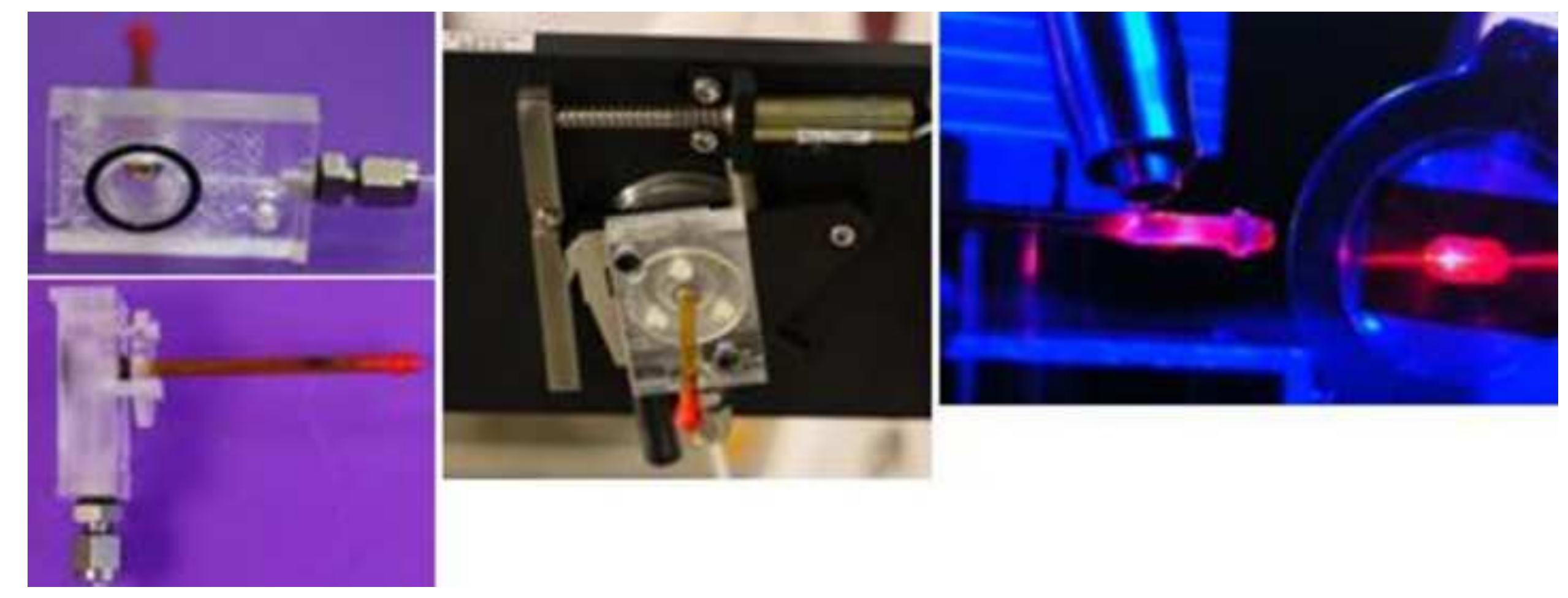


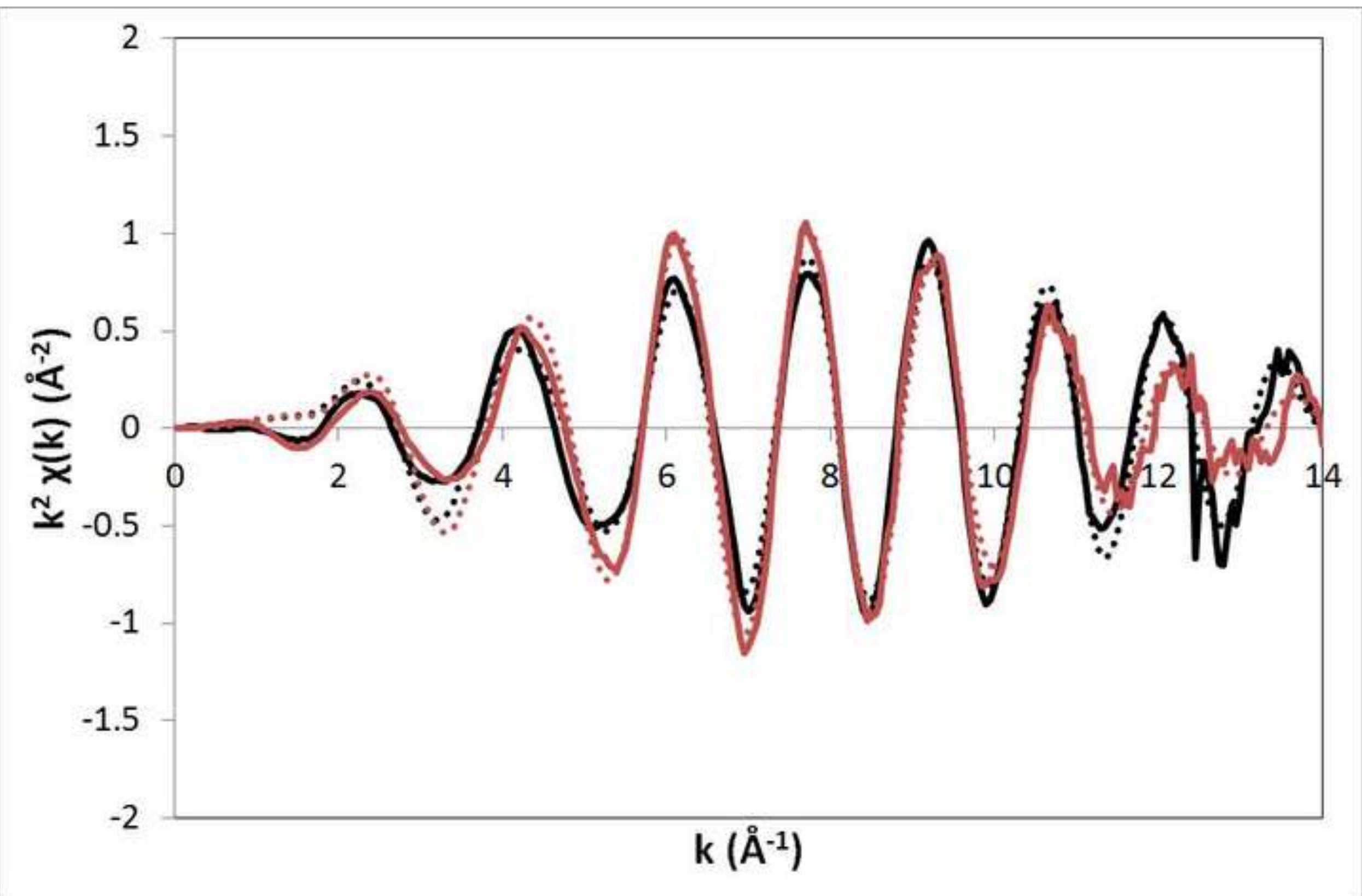


Click here to download high resolution image

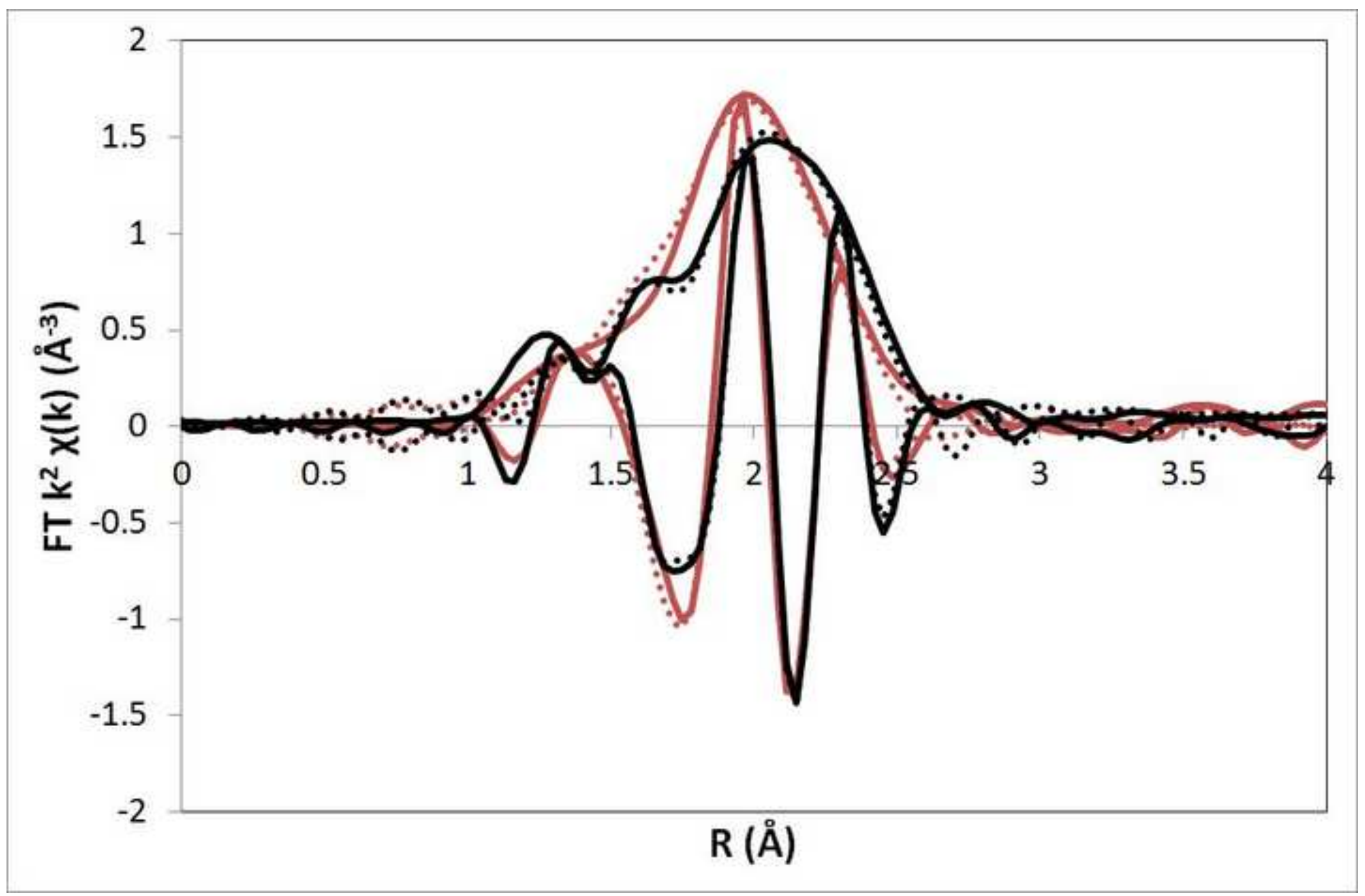


Click here to download high resolution image

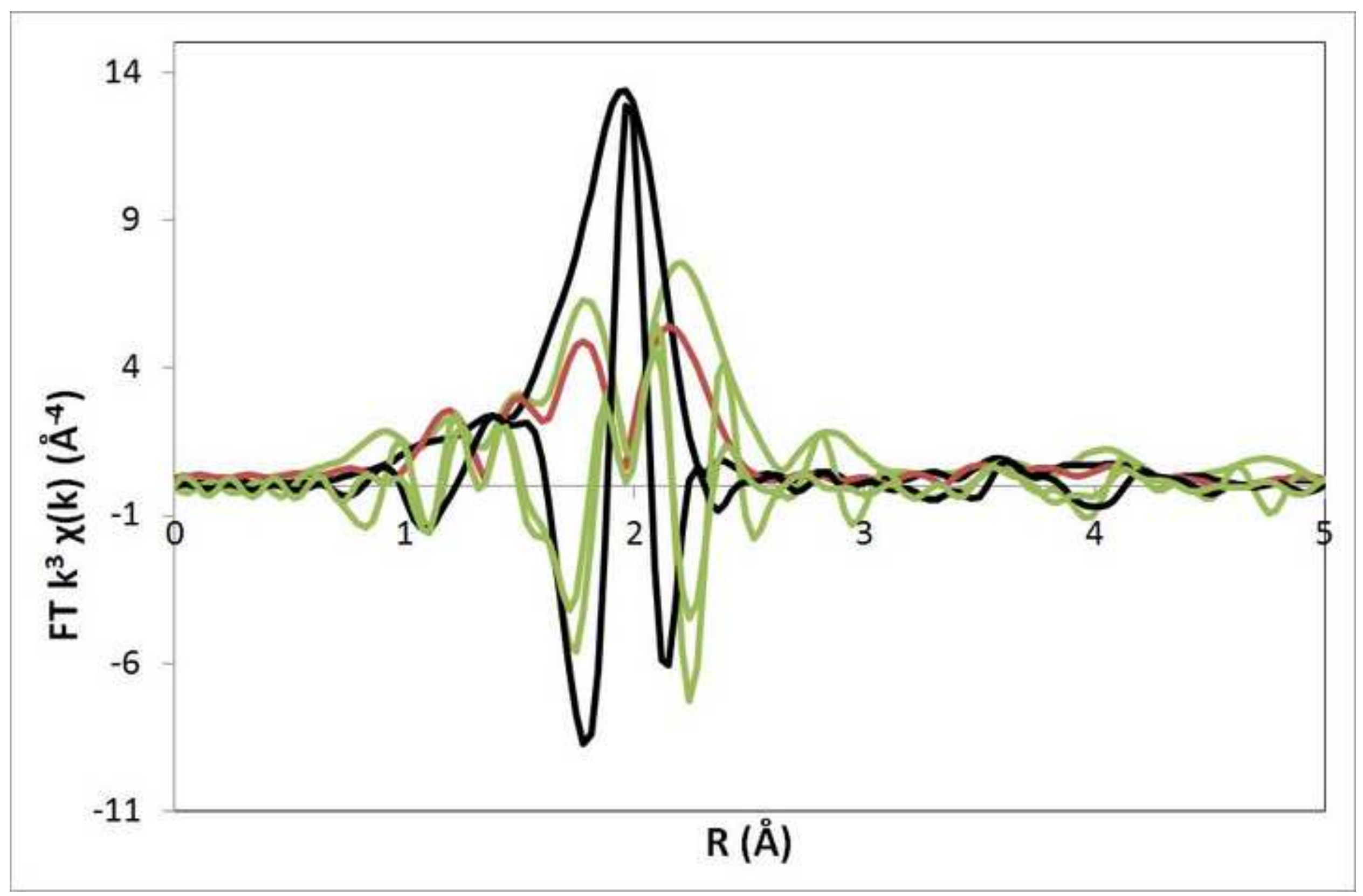




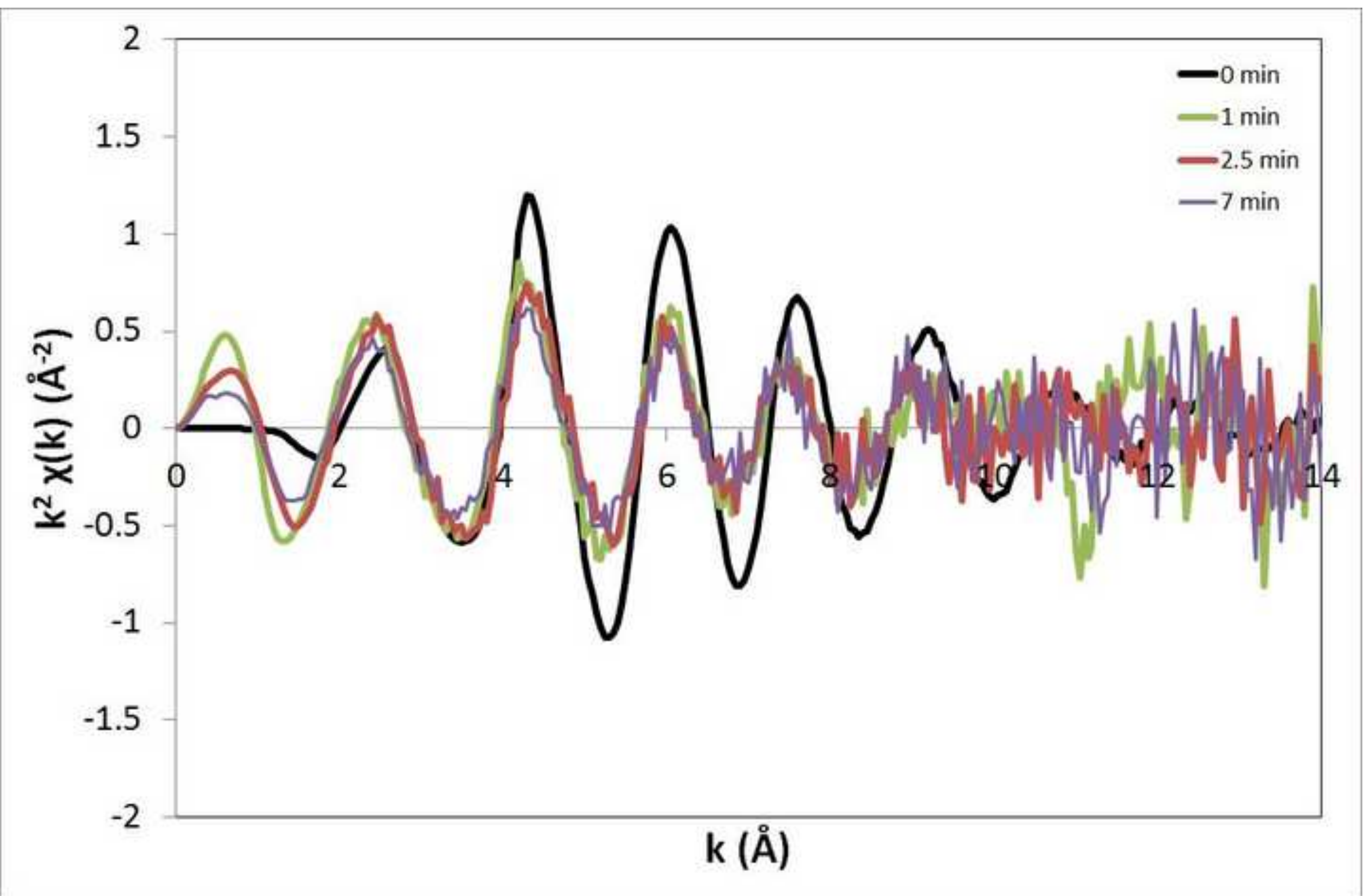


Click here to download high resolution image

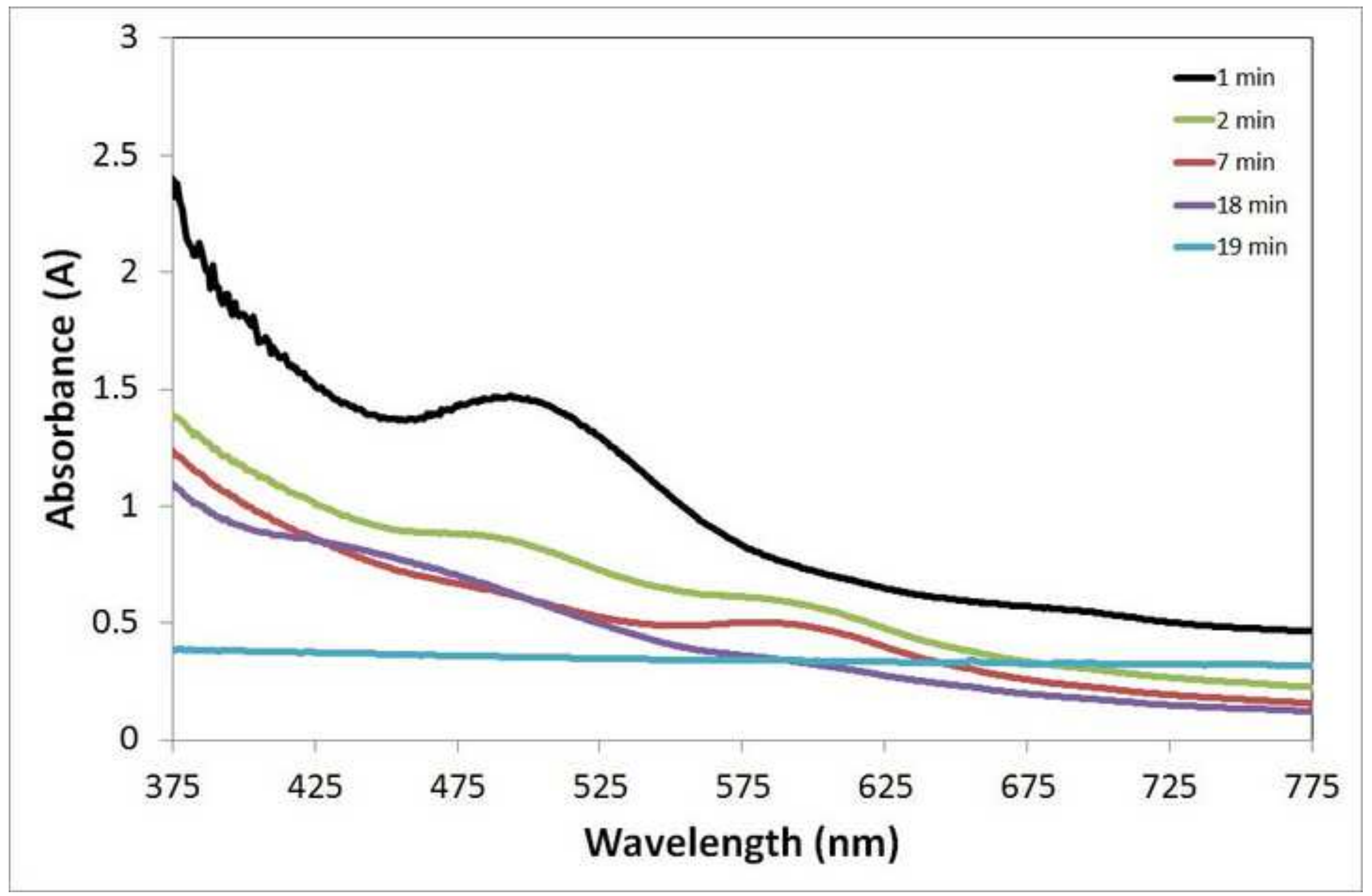




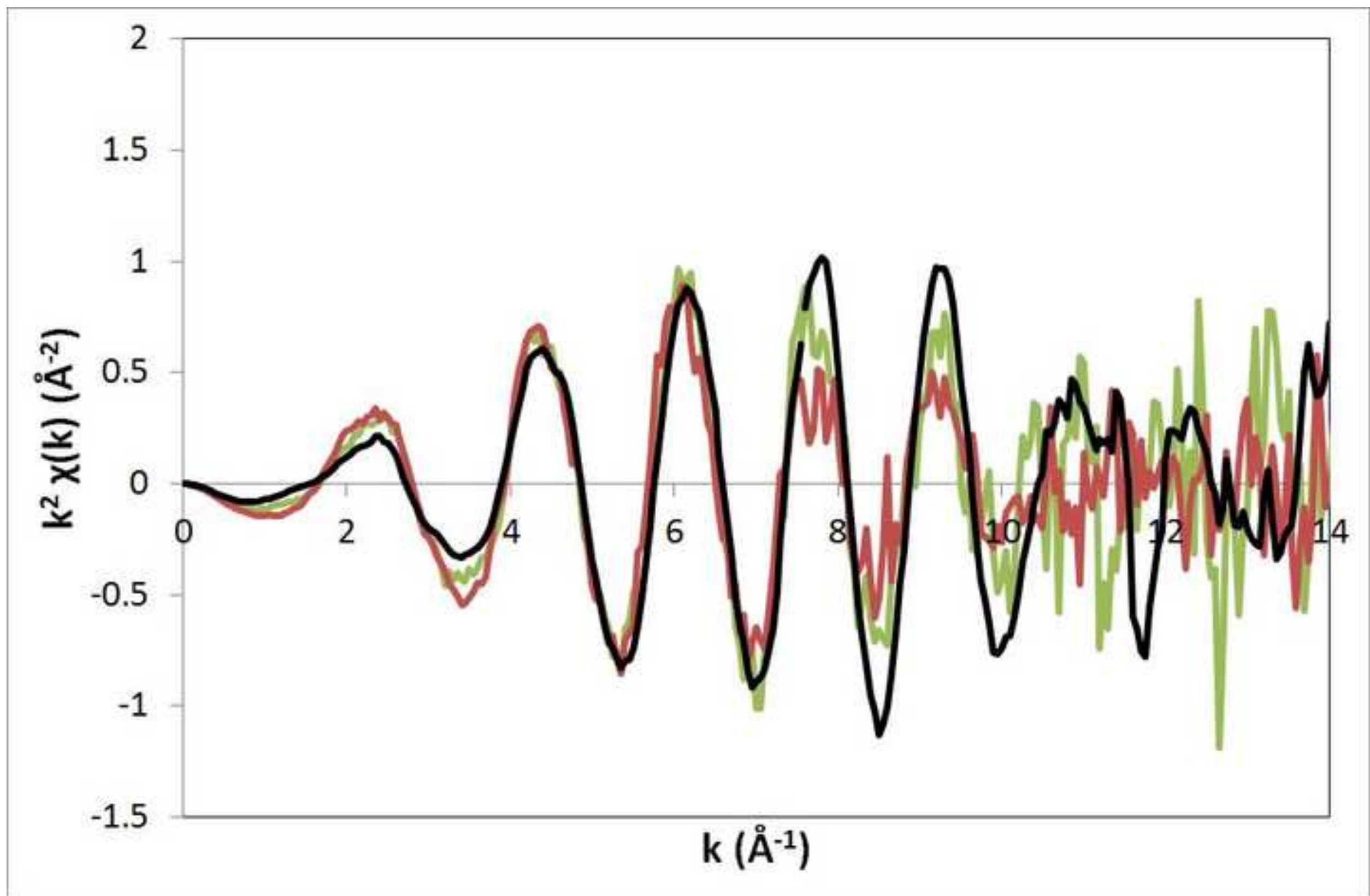




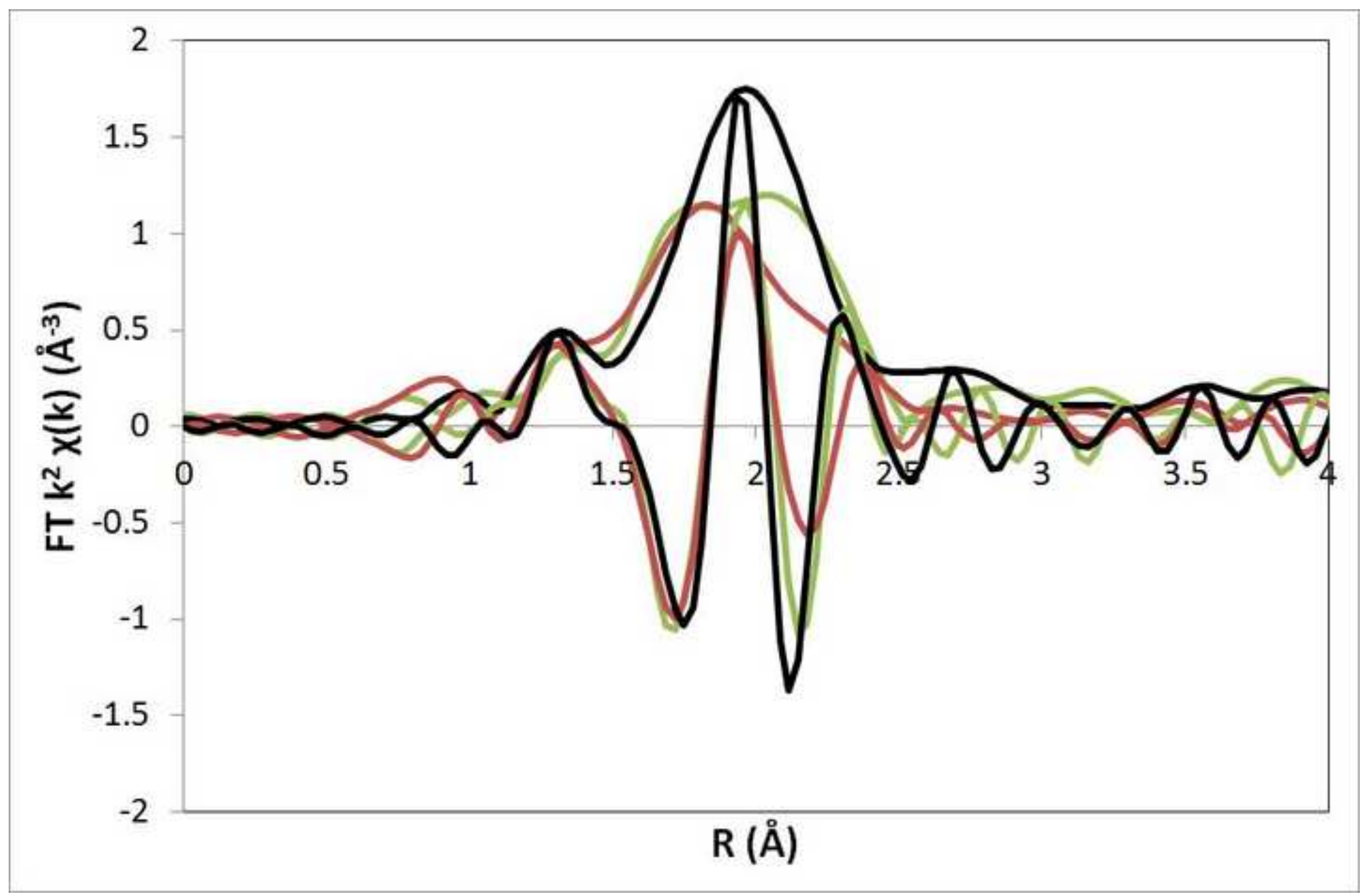


Supplementary Material
Click here to download Supplementary Material: Tromp Mo SFM FQ ESI.pdf

Supplementary Material
Click here to download Supplementary Material: Tromp Mo SFM FQ ESI.pdf

\author{
(a)
}

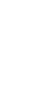

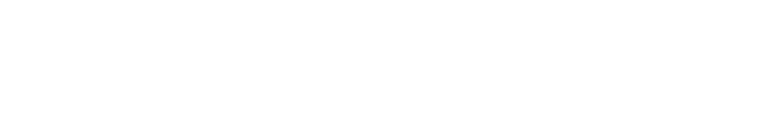
. (1) (1) (1) (1) (1) . . . . . . . . . 
CIF $[\mathrm{MoCl} 3\{\mathrm{tBuS}(\mathrm{CH} 2) 2 \mathrm{NH}(\mathrm{CH} 2) 2 \mathrm{StBu})]$
Click here to download Supplementary N

Click here to download Supplementary Material: 10sab04a [MoCl3(tBuSNS)].txt

Click here to download Supplementary Material: 10sab04a [MoCl3(tBuSNS)] txt

\author{
aterial: 10sab04a [MoCl3(tBuSNS)].txt
}

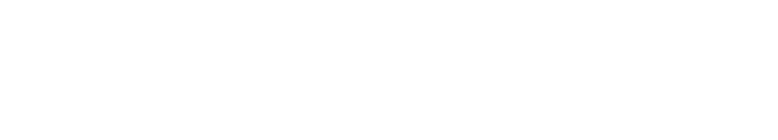


CIF [MoCI3([9]aneS3)]
Click here to download Supplementary Material: 09sab01a [MoCl3([9]aneS3)].txt

CIF [MoCI3([9]aneS3)]
Click here to download Supplementary Material: 09sab01a [MoCI3([9]aneS3)].txt

$\mathrm{CIF}[\mathrm{MoCl} 3([9] \mathrm{aneS} 3)]$
Click here to download Supplementary Material: 09sab01a [MoCl3([9]aneS3)].txt

$\sqrt{20}$

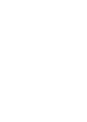

$\sqrt{20}$

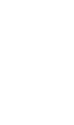

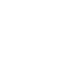

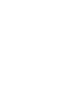

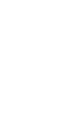
(1)

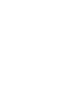
( ( . -

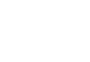

$\sqrt{2}$

